\title{
CONTINENTAL SHELF PROCESSES AFFECTING \\ THE OCEANOGRAPHY OF THE SOUTH \\ ATLANTIC BIGHT \\ Progress Report
}

Leonard J. Pietrafesa

and

Richard D'Amato

Nonartment of Geosciences
North Caroline State University

Raleigh, North Carolina 27607

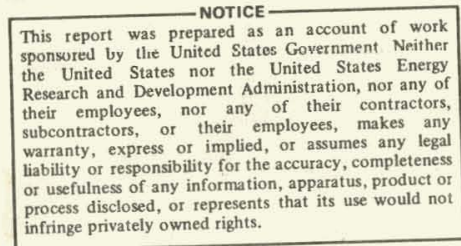

Date Published - March 1977

NOTICE

THIS DOCUMENT WAS PREPARED AS AN ACCOUNT OF WORK SPONSORED BY THE UNITED STATES GOVERNMENT. NEITHER THE UNITED STATES NOR THE UNITED STATES ENERGY PESTARCH ANO DEVLLOPMENT ADMINISTRATION, NOR ANY OF THE!R EMPLOYEES, NOR ANY OF THEIR CONTRACIOES, SUECONIRACIORS, OR THER EMPLOYEES, MAKES ANY WARRANTY, EXPRESS OR IMPLIED, OR ASSUMES ANY LEGAL LIASILITY OR RESPONSIBILITY FOR THE ACCURACY, COMHETENESS OR USEFULNESS OR ANY INFOLMAMTION, ANAMATUS, PRODUCI OR PROCESS DISCIOSED. OR REPTESENTS THAT ITS USE WOUID NOI INFRINGE PAVATEXY. OWNES RIGHTS,

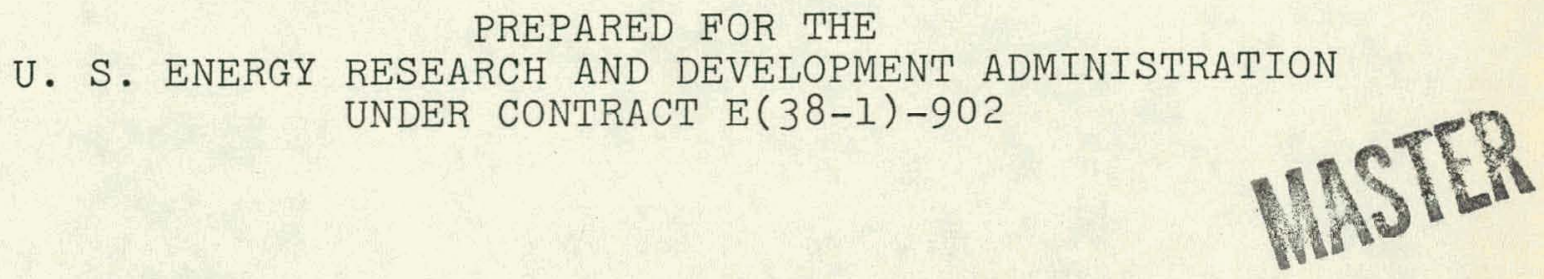




\section{DISCLAIMER}

This report was prepared as an account of work sponsored by an agency of the United States Government. Neither the United States Government nor any agency Thereof, nor any of their employees, makes any warranty, express or implied, or assumes any legal liability or responsibility for the accuracy, completeness, or usefulness of any information, apparatus, product, or process disclosed, or represents that its use would not infringe privately owned rights. Reference herein to any specific commercial product, process, or service by trade name, trademark, manufacturer, or otherwise does not necessarily constitute or imply its endorsement, recommendation, or favoring by the United States Government or any agency thereof. The views and opinions of authors expressed herein do not necessarily state or reflect those of the United States Government or any agency thereof. 


\section{DISCLAIMER}

Portions of this document may be illegible in electronic image products. Images are produced from the best available original document. 


\section{Table of Contents}

\section{Page}

ABSTRACT

1

SCOPE

2

SIGNIFICANT RESULTS'

14

SUMMARY OF ACCOMPLISHMENTS

40 
The objectives of the project were to determine the physical/ dynamical processes controling/affecting the distribution of phytoplankton nutrients on the continental shelf in the South Atlantic Bight. The initial objectives were to determine the short term, 1.e., 2 to 10 day and longer term flux of nutrients onto the continental sheff: This is clearly related to the more general problem of comblined physical and blogenic control of phytoplankton nutrients.

Pietrafesa (North Carolina State University) and Atkinson (Skidaway Institute of Oceanography) conducted a pilot experiment on the "Summer" (August-September) and "Fall" (October-December) circulation and hydrography on the North Carolina continental shelf in 1975. The experiment did produce the first results from which processes, their causes and effects, and their frequency of occurrence and persistence, could be appreciated and studied. The current meter data suggested that there is both tidal and sub-tidal energy on the North Carolina shelf and that the sub-tidal variability is strongly atmospherieally and Gulf Stream influenced.

Encouraged by the relative success of the 1975 pilot study, Atkinson; Pietrafesa, Dunstan (Skidaway Institute of Oceanography) and Paffenhofer (Skidaway Institute of Oceanography) conducted a more extensive and comprehensive fleld experiment in onslow Bay during the period June thru September, 1976. The objectives of this second year. (of funding) experiment included both the direct measurement of the along-shelf, cross-shelf and vertical structure of the "late Spring-Summer-eariy Fall" current, temperature, conductivity and pressure flelds from fixed point, vertical moorings and a continuation of the hydrographic and biological sampling by SKIO personnel.

Additionally, the moorings were re-established in December, 1976 and are scheduled to be retrieved in late April, 1977. During this period, Lee (University of Mlami), Atkinson and Pietrafesa are co-ordinating a Winter/Spring. pllot experiment. This experiment, if successful, will yield the first major alongshore South Atlantic Bight physical data. 
Scope :

The objectives of this progress report are to provide a brief description of the scope of the investigations undertaken and some of the results which have been obtained.

The objectives of the project were to determine the physical/ dynamical processes controlling/affecting the distribution of phytoplankton nutrients on the continental shelf in the South Atlantic Bight. The initial objective was to determine the short term, i.e., 2 to 10 day flux of nutrients onto the continental shelf. This is clearly related to the more general problem of combined physical and biogenic control of phytoplankton nutrients. Pletrafesa and Atkinson conducted a pilot experiment on the "Summer" (August-September) and "Fall" (October-December) circulation and hydrography on. the North Carolina continental shelf in 1975. These field experiments consisted of two temperature sensor and current meter moorings during each period of observation. An intensive hydrographic grid was surveyed while the fixed position time series were being recorded. The mooring locations and hydro grid are depicted in Figures 1,$2 ; 3,4$, and 5. While several of the instruments functioned imperfectly, the experiment did produce the first results from which processes, their causes and effects, and their frequency of occurrence and persistence, could be appreciated and studied. The current meter data suggested that there is both tidal and sub-tidal energy on the North Carolina shelf and that the sub-tidal variability is strongly atmospherically and Gulf Stream influenced. Low-passed and fast fourier transformed 


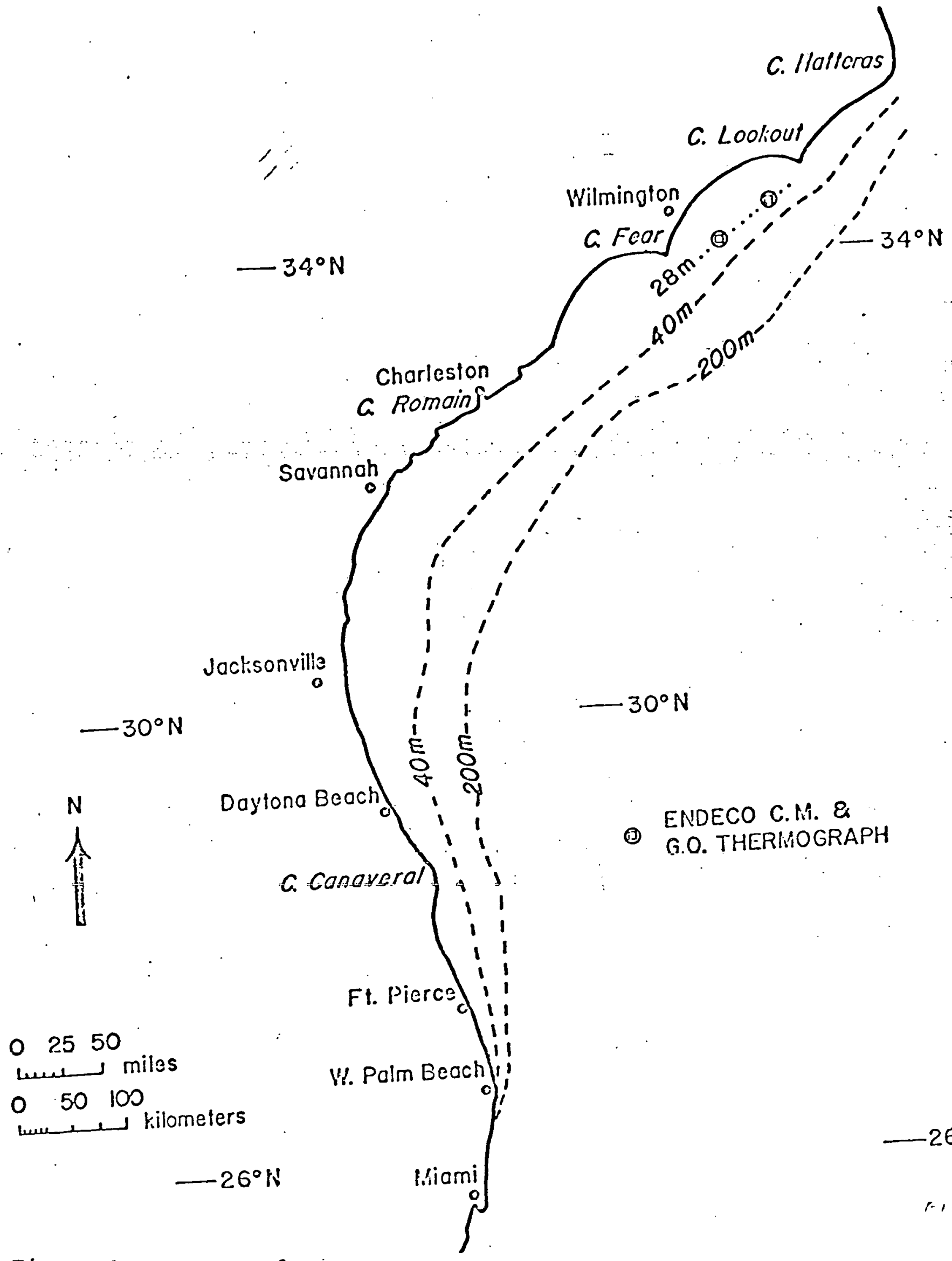

Figure 1 . 

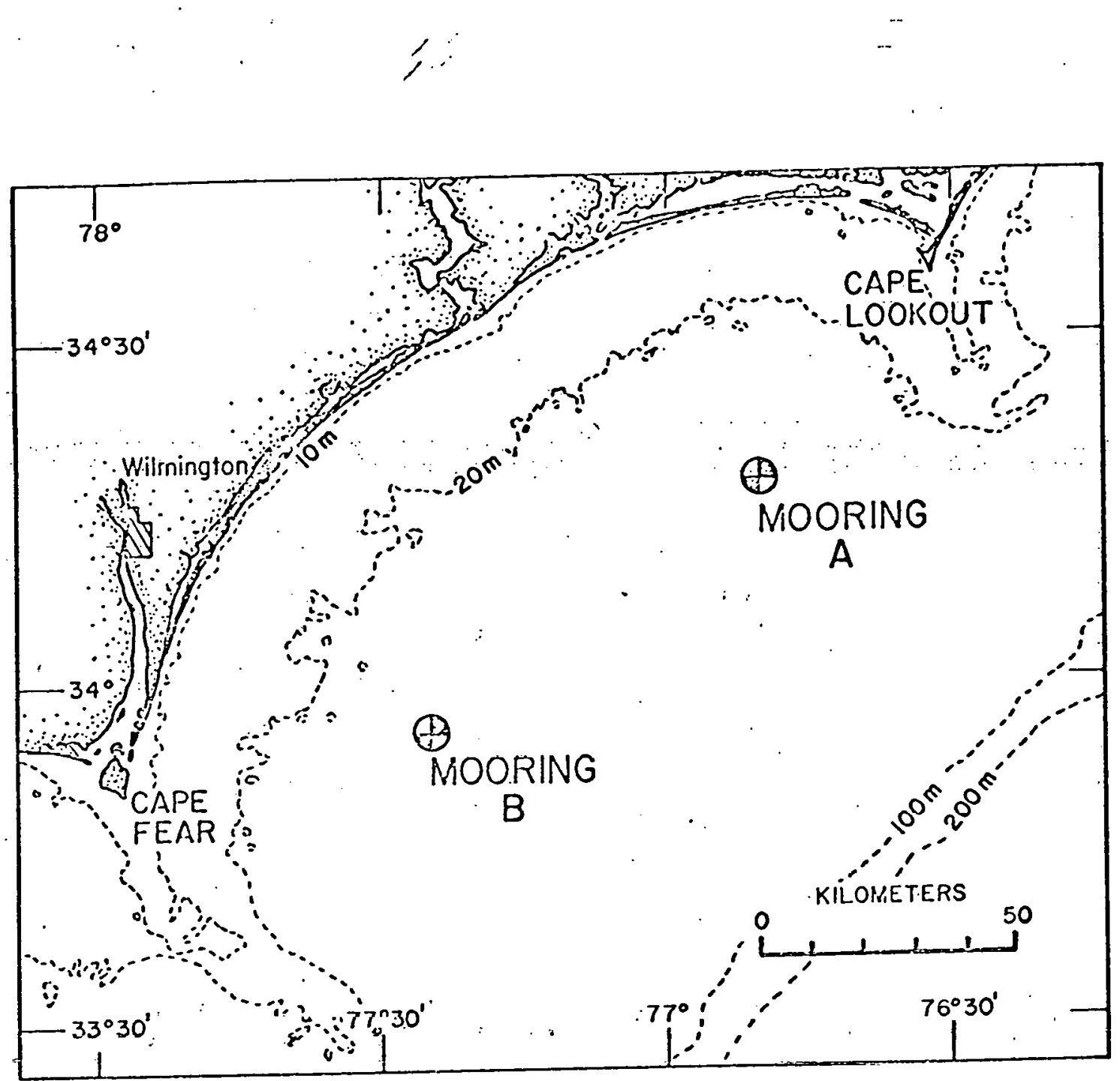

Figure 2. 


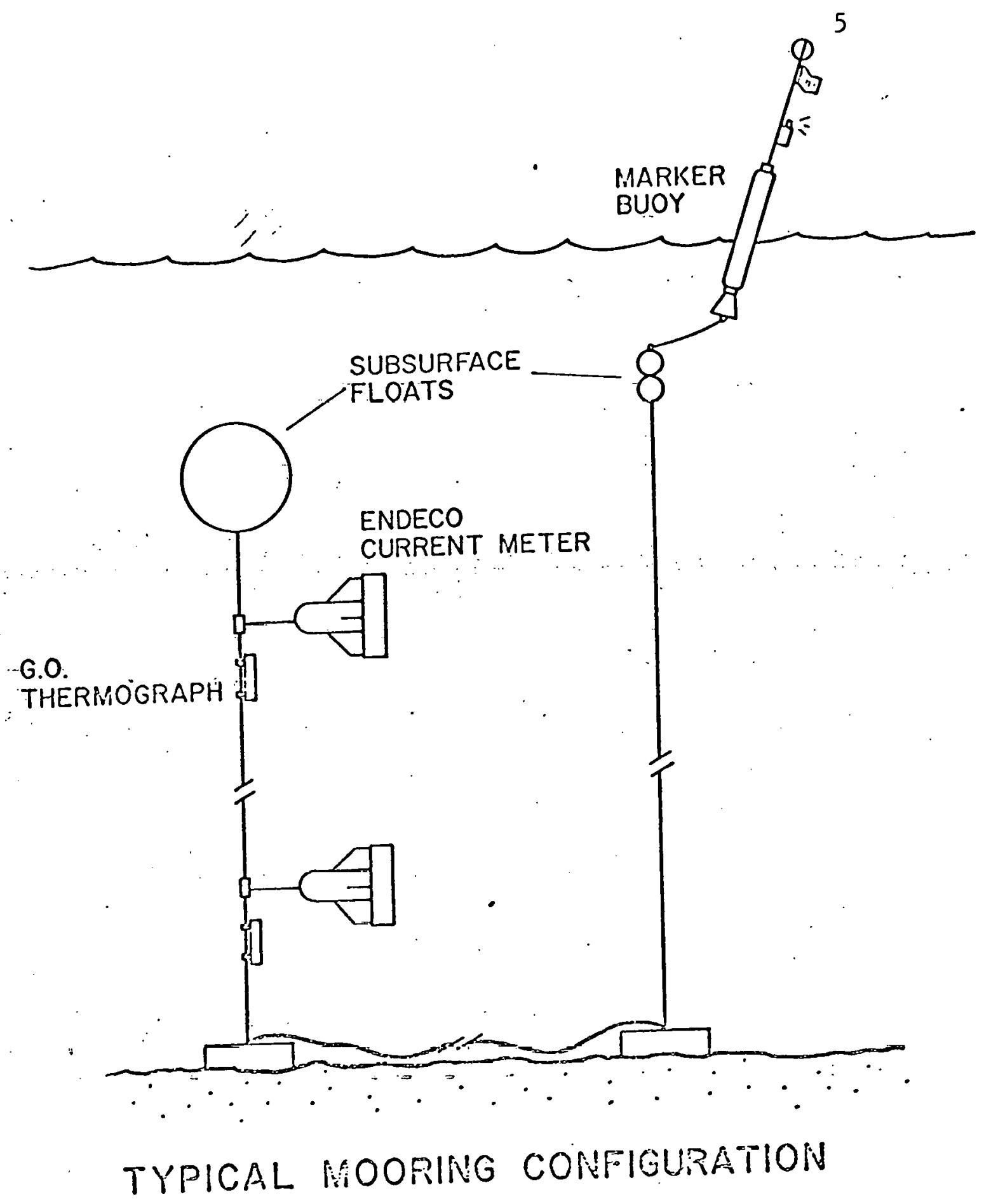

Figure 3. 

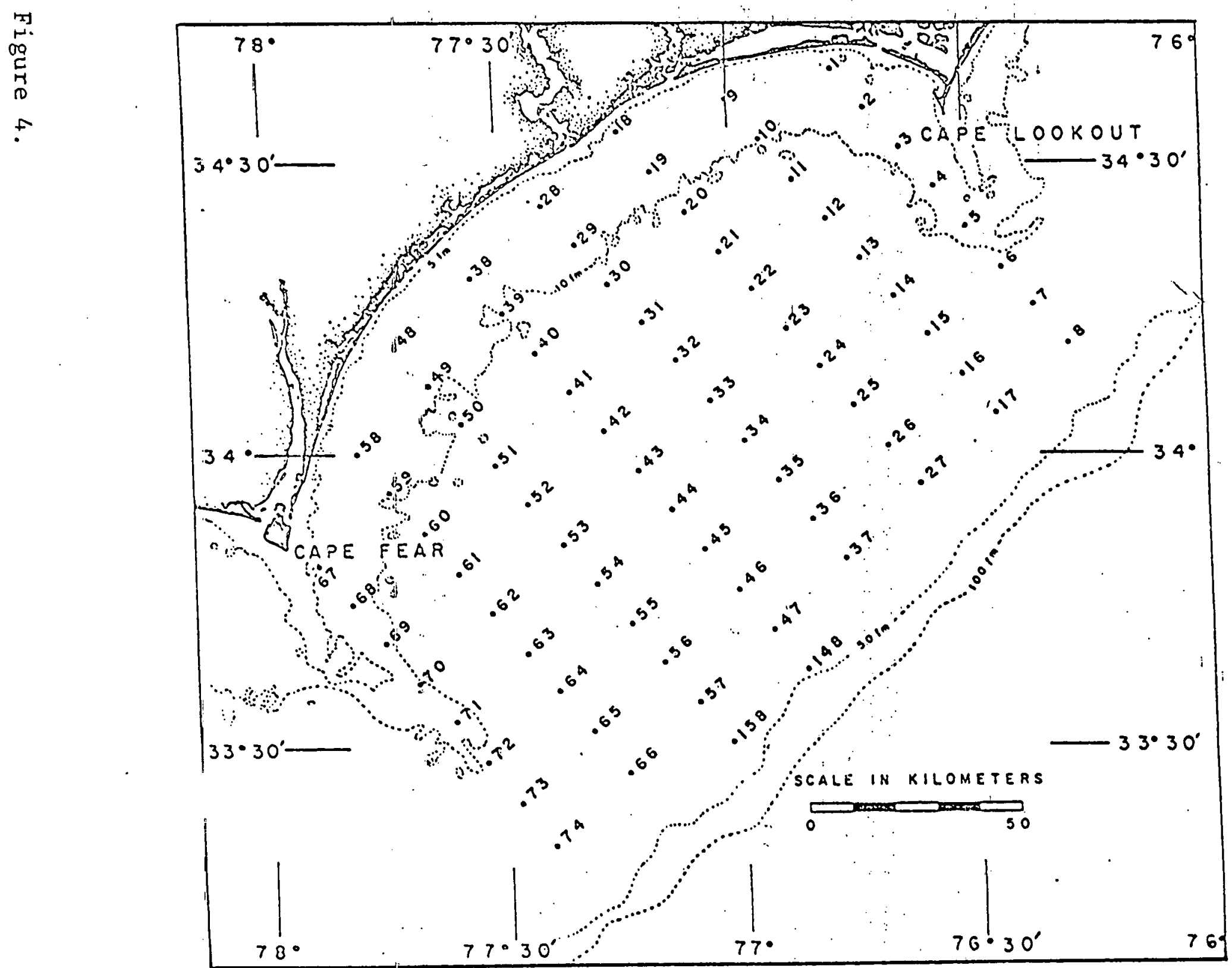


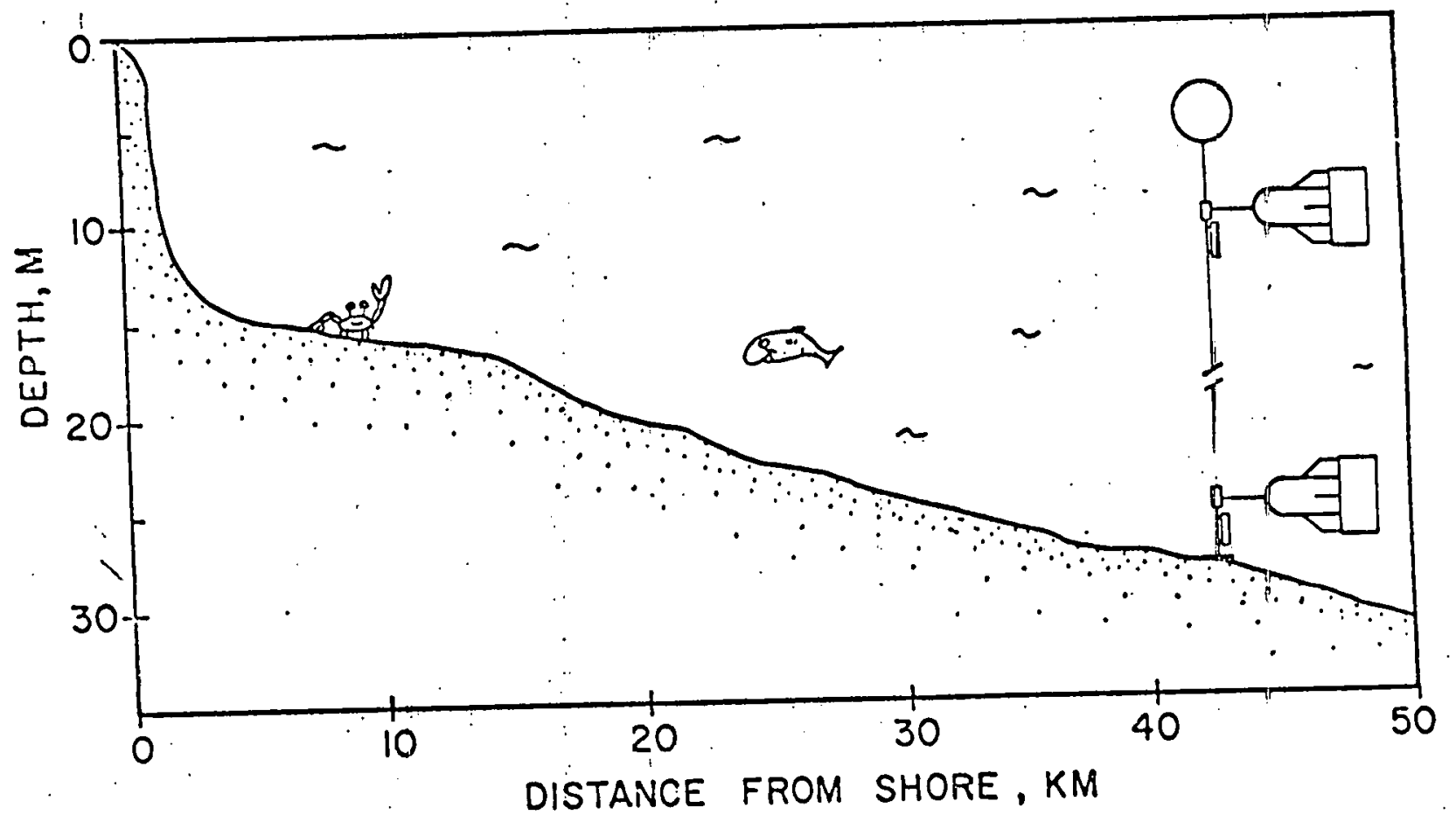


coastal atmospheric, wind speed and direction, pressure and temperature and coastal sea level data indicate that there are sequences of broad band energy peaks with obvious correlations between the different data within the banded spectra. Herein, 1t was felt that investigations of particular processes or event oriented experiments could be planned, with more appropriate guidelines. Additionally, the hydrographic and biological data collected by Skidaway Institute of Oceanography (SKIO) personnel (and alded by North Carolina State University staff and students), seems to have a sound basis in the physical events that were observed, 1.e., recorded contemporaneously in the current data.

Encouraged by the relative success of the 1975 pilot study, Atkinson, Pietrafesa,"Dunstan and Paffenhofer conducted a more extensive and comprehensive field experiment in Onslow Bay during the period June thru September, 1976. The objectives of this second year (of funding) experiment included both the direct measurement of the along-shelf, cross-shelf and vertical structure of the "late Spring-Summer-early Fall" current, temperature, conductivity and pressure fields from fixed point, vertical moorings and a continuation of the hydrographic and biological sampling, along the 1975 grid (Figure 4) by SKIO personnel. The mooring locations and vertical configurations are shown in Figures 6 and 7. A total of 8 Endeco and General Oceanic current meters and thermographs were used at. the 30 meter locations (sites $A$ and B) and 8 Aanderaa RCM-4 sensors were used at the three 45 meter and one 70 meter sites (C, D, E and F). Usable data was obtalned from the 8 Endeco-General Oceanics elements at $A$ and $B, 2$ Aanderaa 


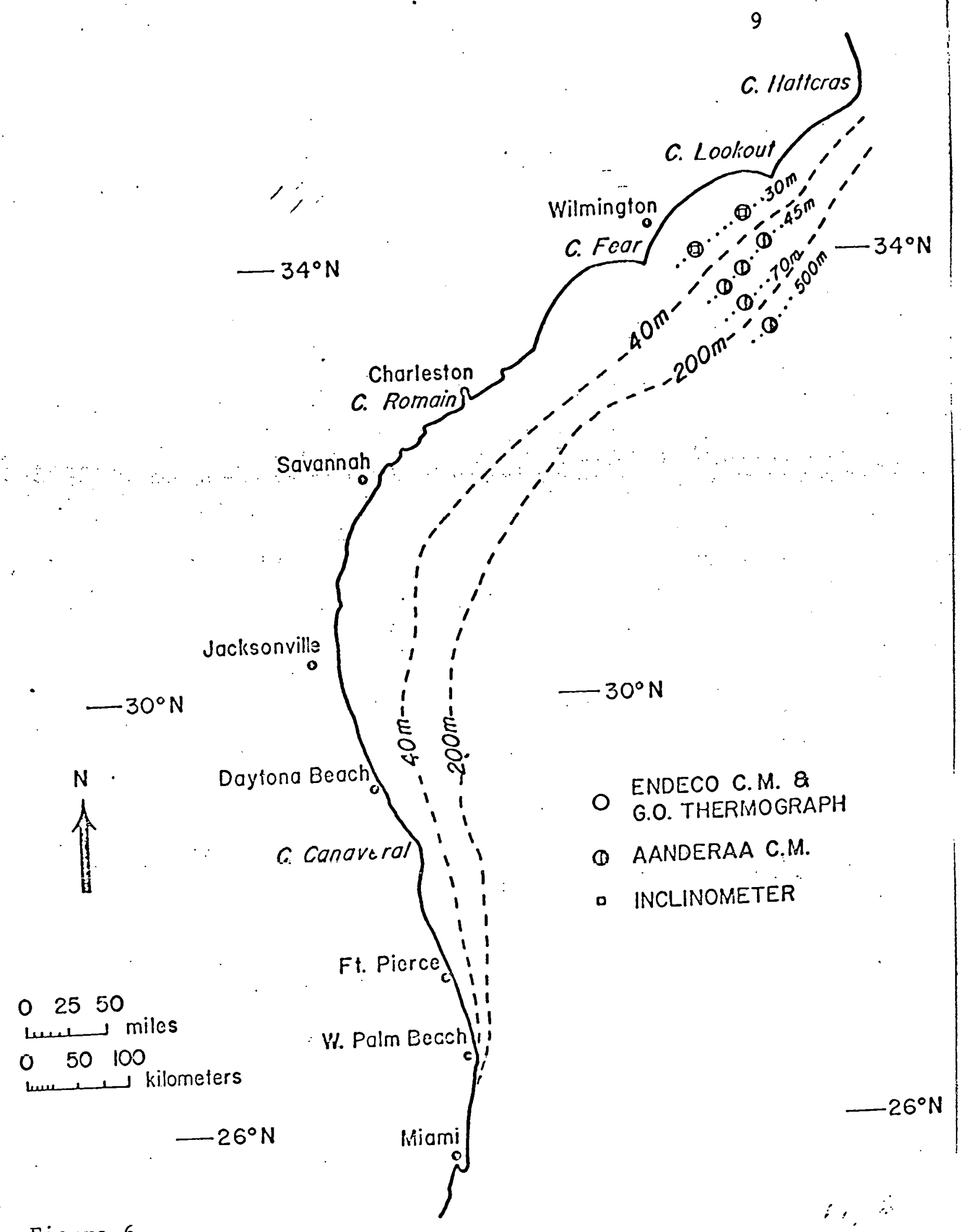

Figure 6 . 

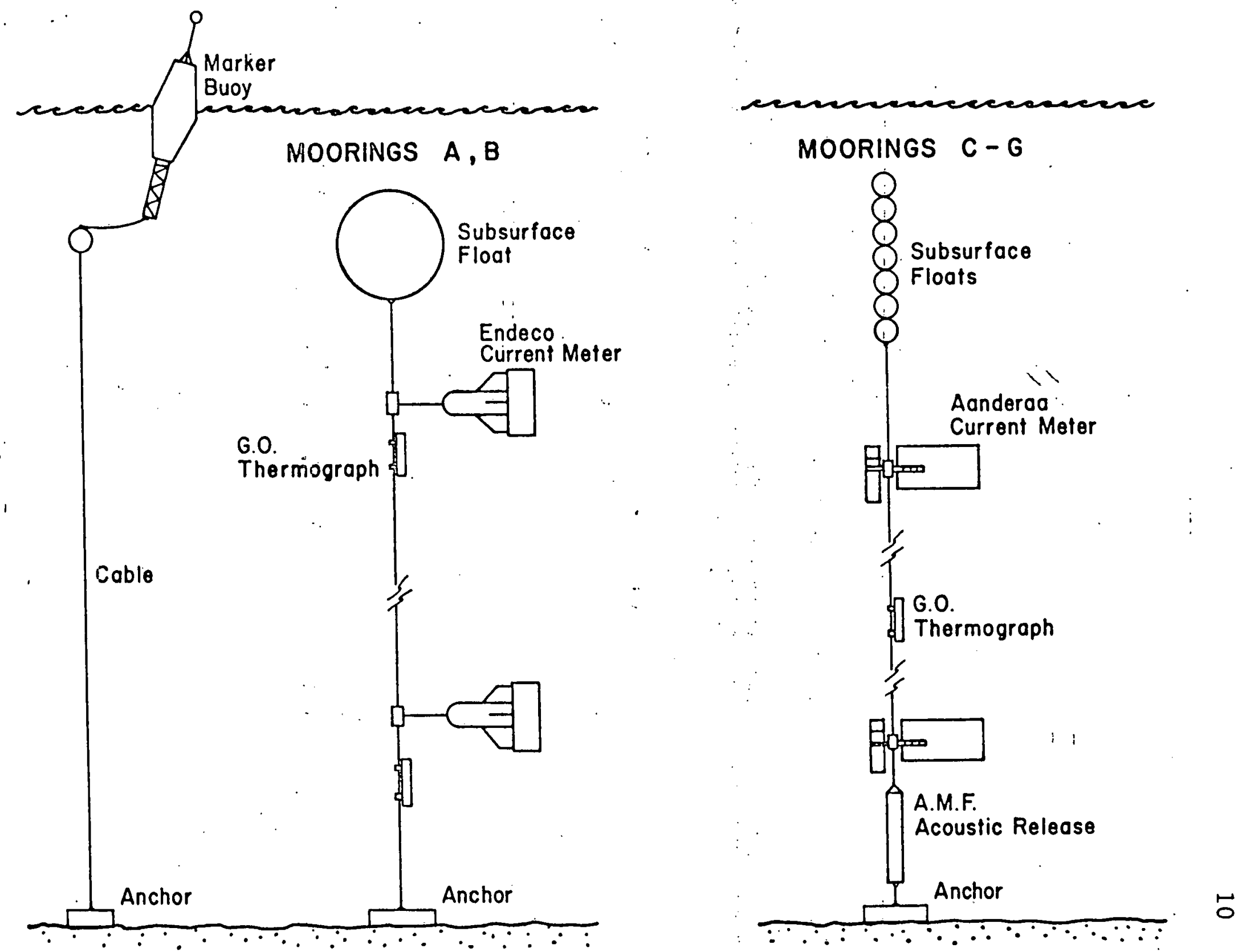

\section{TYPICAL MOORING CONFIGURATIONS}


sensors at $C, 2$ Aanderaa sensors at $D, 2$ Aanderaa sensors at $E$ and 1 Aanderaa sensor at F. Several major and minor quasisynoptic hydrographic and biological surveys were made during the moored array experiment to. study the variability_of the shelf water and blological properties and to better determine the spatial and temporal distributions therein. Meteorological and coastal sea level data have been collected from the stations listed in Tables 1 and 2. Wind stress vector components have been/are being computed from the wind vector components using a quadratic law and low pass and high pass time series have been generated by filtering with a Lanczos filter taper with the response envelope shown in Figure 8: Hourly sea level heights from coastal tide gauges were low pass filtered with the Lanczos filter taper, thereby segregating the long period sea level fluctuations from the semidiurnal and diurnal tidal signals. Computations of auto and cross spectra, phase and coherence squared as well as graphs of varlance versus logarithm of frequency have been made and are in- :

. cluded in the accompanying report.

Additionally, the moorings were re-established in December, 1976 and are scheduled to be retrieved in late April, 1977. During this period, Lee (University of Miami) and Pietrafesa are co-ordinating a Winter/Spring pilot experiment. The North Carolina State University - mooring locations are depicted in Figure 9. This experiment, if successful, will yield the first major alongshore South Atlantic Bight physical data. 
A.

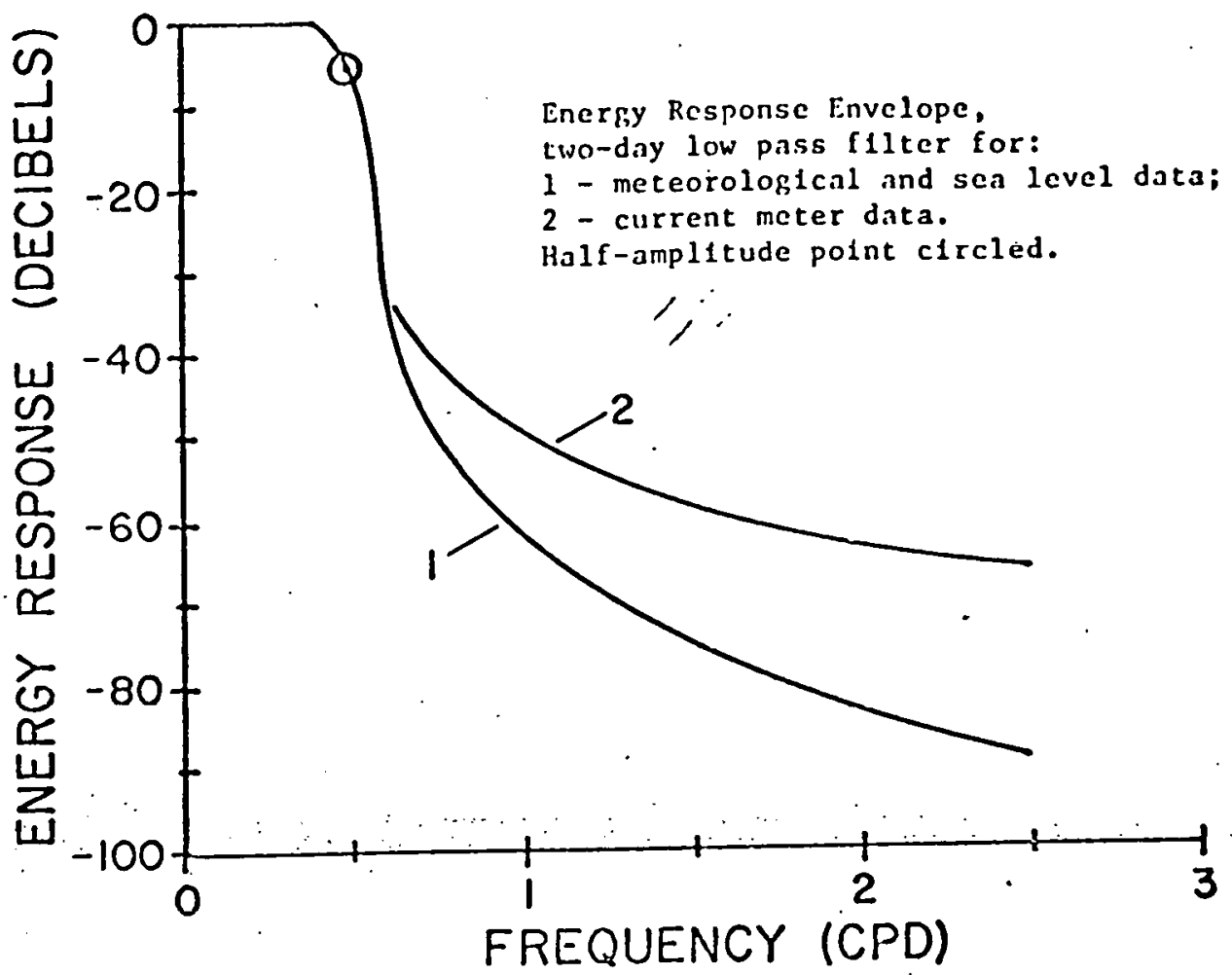

B.

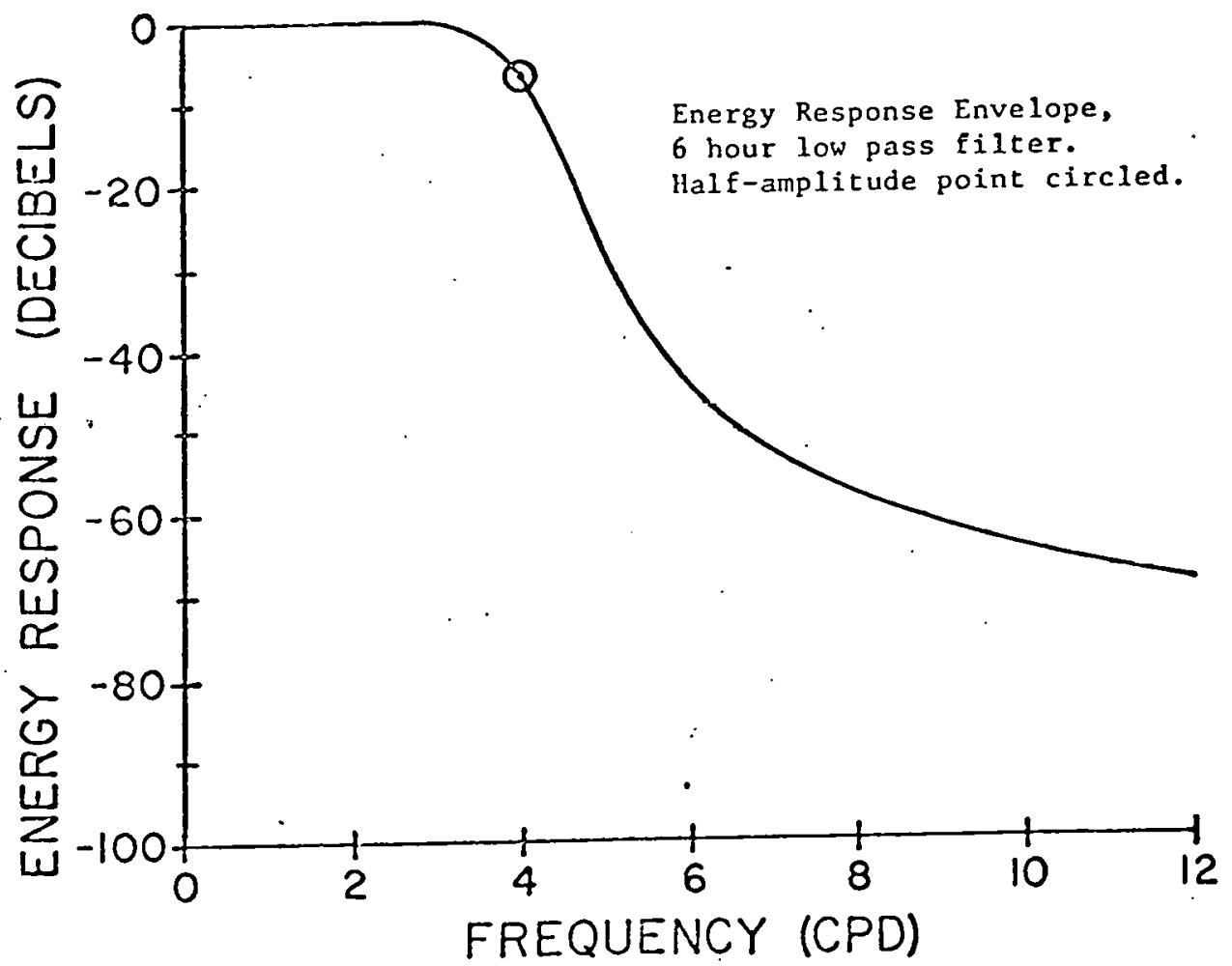

Figure 8. 


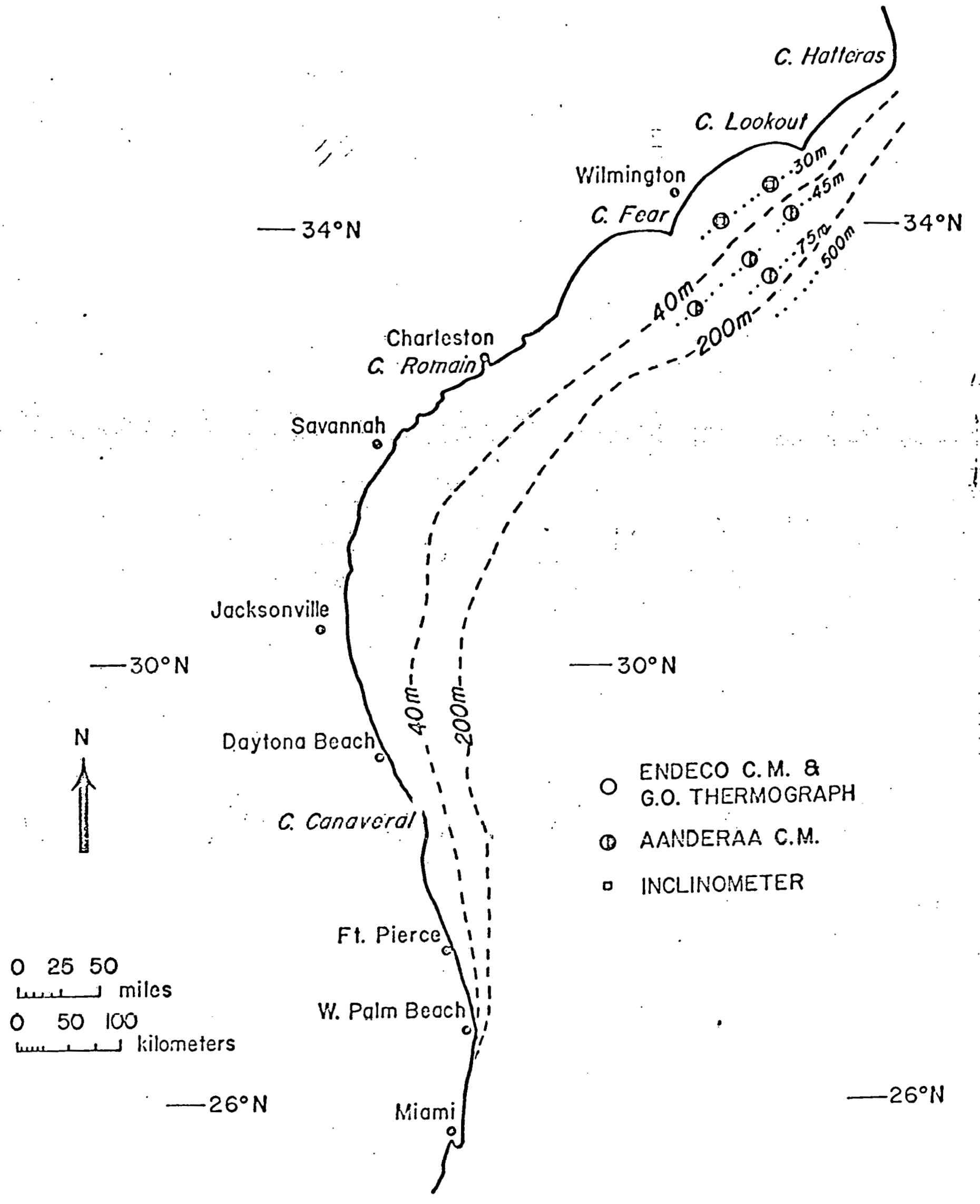

Figure 9. 
Significant results:

These data products indicate some preliminary results of the investigations with obvious particular interest being given to the determination of the tidal to subtidal variabllity with regard to the possible driving mechanisms supporting the behavior of the regime.

One can begin by examining representative kinetic energy spectra which have been generated using standard time-series analysis techniques. It should be noted herein that the low frequency cutoff is inversely proportional to the length of the data record being analyzed and we are severely limited at this point in making any credible estimate of the shape of the kinetic energy spectrum over more than several decades of frequency range.

The computed spectra' indicate source apparently fundamental features of the wind and current variability in the region of the Carolina Capes Shelf. From the spectra it appears that the wind stress has fluctuations which have periods ranging from a half day to a week and are built into the atmospheric cyclones which progagate up along the eastern U.S. coast w1th characteristic periods of several days to several weeks.

The current spectra show sharp peaks at the sem1-diurnal frequency and peaks at the diurnal frequency. It is projected that the K.E. density will assume a depth to the minus three haves power law, at the semi-diurnal frequency. This law is derived from simple shallow-water wave theory. Since the current meter moorings, during the 1975 experiment, were located along 
the same isobath over the deployment periods, it is difficult to do more than speculate on the spatial structure of the tides, in this area.

The six mooring array, established in summer, 1976 in Onslow Bay (and re-established in December, 1976) should help in the construct of some simple tidal models for the immediate future, since the tidal currents are partially predictable, given the deterministic forcing. The questions concerning the role of internal waves, possibly present at tidal frequencies, especially during "summer" conditions, when a strong, transient thermocline feature is evident (Stefansson and Atkinson, 1971; Atkinson et al, 1976) will also be investigated. This latter phenomenon appears across the shelf. Baroclinic tides might also appear at the shelf break over most of the year, given the strong frontal features that persists given the presence of the Gulf Stream at the Shelf break.

Inertial frequency components are also evident in the current spectra. Meteorological transients in the form of anti-cyclonically rotating winds can locally generate near inertial signals in the current field. This sort of meteorological feature is certainly evident in the area.

On the frequency and of the current spectra, one can infer shelf and edge wave type modes with characteristic periods of the order several days to several weeks. There are also Gulf Stream meanderings and eddy, shingle, filiment shedding processes which presumably yield signals in the data, but these signals are yet to be definitively resolved. 
It would appear that the subtidal currents observed at sites $A$ and $B$ are strongly wind dominated. The lower frequency signals could consist of energy derived from meteorological forcing and from the propagation of this frequency energy onto the shelf from offshore. The actual partition will be more fully investigated with the results from the Summer, 1976 and Winter/Spring 1977 studies. There is no doubt that offshore and shelf break phenomena are an important source of energy for the outer and perhaps inner Carolina Capes Shelf but there now seem to be insights into a more definite relationship between the direct mechanical forcing of the wind and the current spatial and temporal varlability.

A direct effect of this wind can be expressed in the horizontal; on-shore-offshore pressure gradient consisting of tidal and nontidal components. Using an inverse barometer rule, $10 \mathrm{mbar}$ pressure difference alongshore would result in sea surface slopes of order 5(10-7), contributing $5 \mathrm{~cm} / \mathrm{sec}$ to the general circulation. Furthermore, pressure changes in resonance with various free wave modes, such as shelf waves, could result in geostrophic currents of the order of cms/sec.: Sharp pressure fronts moving onto the shelf could also put considerable energy into a free seiche mode. Additionally, there is evidence, the 3-5 day energy peak in the current-meter spectra, that forced "Shelf wave" oscillations, can exist along the North Carolina coast and may in fact be topographically encouraged or trapped. These forced modes could be accompanied by currents of the order of $10^{\prime} \mathrm{s}$ of $\mathrm{cms} / \mathrm{sec}$.

Several major meteorological events occurred during the 
summer, 1976 moored array experiment, the most prominent of which was Hurricane Belle. These storms produced current transients.. which are distinctiy visible in the unfiltered data records. This data set is distinctly unusual since we are presently aware of only two other data séts taken on a continental shelf under direct hurricane forcing. Fortuitously, these other time series were obtained during Belle by NOAA, in the region of the New York Bight, and by the Chesapeake Bay Institute, in Virginia nearcoastal waters. These data, when intercompared, will afford us a rare look at the response of several continental margins to hurricane forcing.

At the edge of the shelf, there seems to be a considerable amount of exchange and mixing of slope and shelf waters: Strong reversing currents driven by the diurnal (and to lesser extent semi-diurnal) tide could cause local mixing and effectively pump nutrients and other materials up onto the shelf without much net mass flux. Additionally, internal tides may break or mix near the shelf break and large amplitude internal waves may be observed in the seasonal thermocline, driven by shelf-break tidal forcing may exist. The relative importance of these possible mechanisms for shelf and slope water exchange is not yet known but must be addressed. Also, little is also known about the actual dynamical coupling between the shelf and slope regions, particularly the transmission of low frequency energy from the deep ocean onto the continental shelf and vice versa. It is herein also of note that barotropic topographic Rossby waves could exist and propagate in the area of study. Presumably, the meanderings of the Guif 
Stream could radiate these low frequency motions onto the shelf, but the generating and support mechanisms are not yet known. The low-pass filtered current records obtained during our 1976 Summer shelf experiment suggest that energetic low frequency currents with characteristic periods of 1 to 2 weeks also occur over the outer continental shelf. This observed low frequency variability could be correlated. with meteorological events or could represent energy which has propagated onto the shelf from the deep ocean:

Niller and Mooers have pointed out that the broad West Florida shelf appears to exhibit a "banded" response to various forcing mechanisms, i.e., the response to a particular forcing mechanism may depend critically on local water depth so that different mechanisms may be more effective in exciting motions in different depth zones of "bands". This simple notion of a "banded" response may be applicable to the South-Atlantic continental shelf. We have already suggested that the low frequency currents over the shallower zone of the shelf are essentially wind-driven (at least in winter-time) and in fact may be predictable using meteorological or corrected sea level data. Transient meteorological events can also directly excite continental shelf waves which are nearly trapped to the shelf and slope. Both high frequency (predominantly external and internal tides) and low frequency energy propagate onto the continental shelf from the deep ocean. Sufficient reflection and damping might prevent the offshore-driven low frequency 
motion from propagating into the shallower wind-driven zone of the shelf, and the increased depth and distance from the shore may reduce the direct excitation of shelf wave modes near the shelfbreak so that the outer ghelf currents may be dominated by offshore oceanic sources and little low frequency energy may be radiated into the deep ocean from the shelf except by reflection. If in fact the actual response on the South-Atlantic Bight continental shelf and slope is "banded" or nearly so, then a major simplification occurs in the description and Interpretation of the current field and the chances for useful prediction of the current field are markedly improved.

Finally, we have produced a simple two-dimensional mathematical model of a nutrient distribution in continental shelf waters as a function of the vertical plane conceptual intrusion picture presented by Blanton (1971). The nutrient distribution model (Hofmann, et al, 1977) is included as an accompanyment to this proposal.

Examples of the data sets are presented in the following figures; Figures 10-29. The figures are a product of the geophysical time series analysis program developed at North Carolina State University under ERDA funding. 

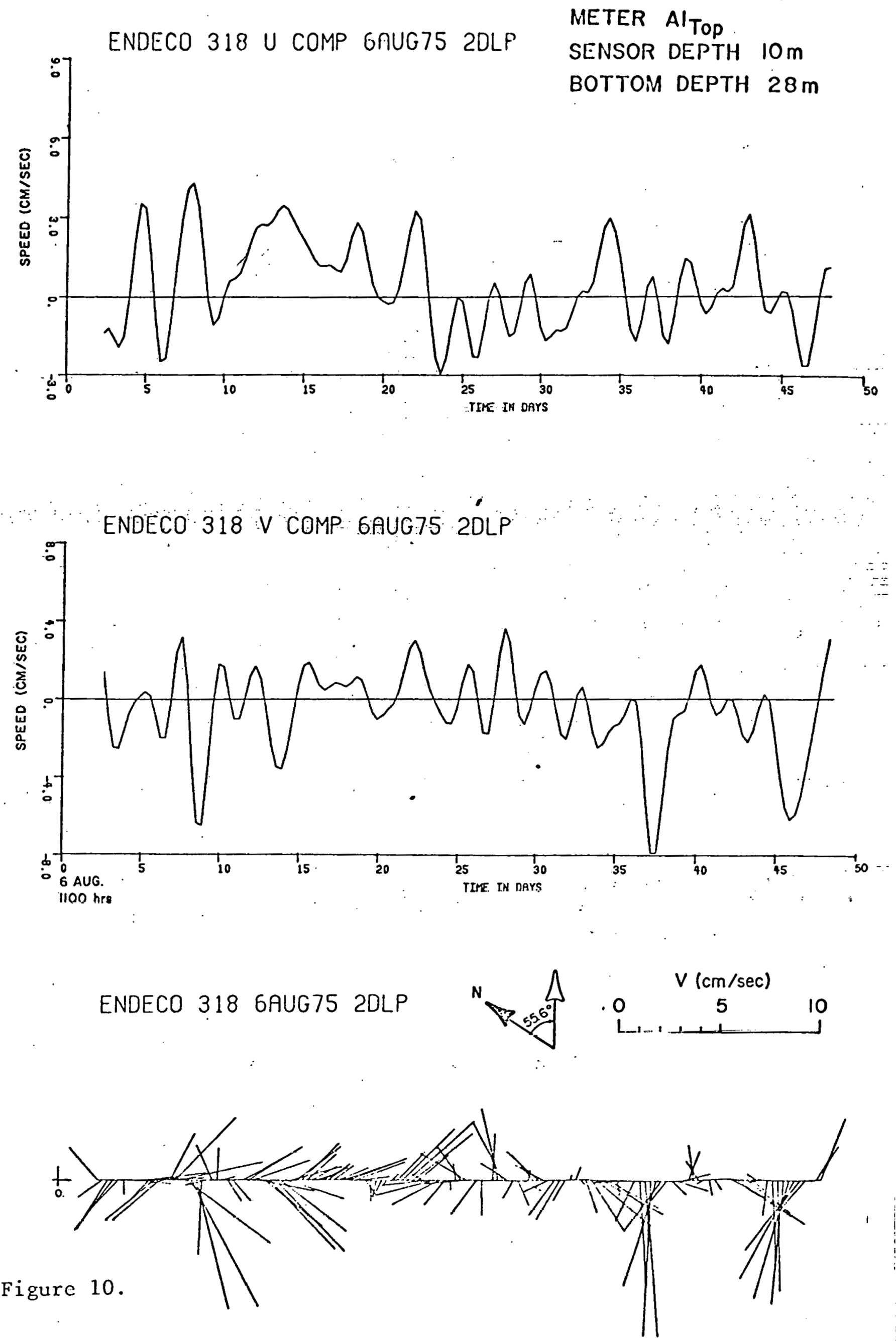
ENDECO 318 U CUMP 6AUG75 2DLP

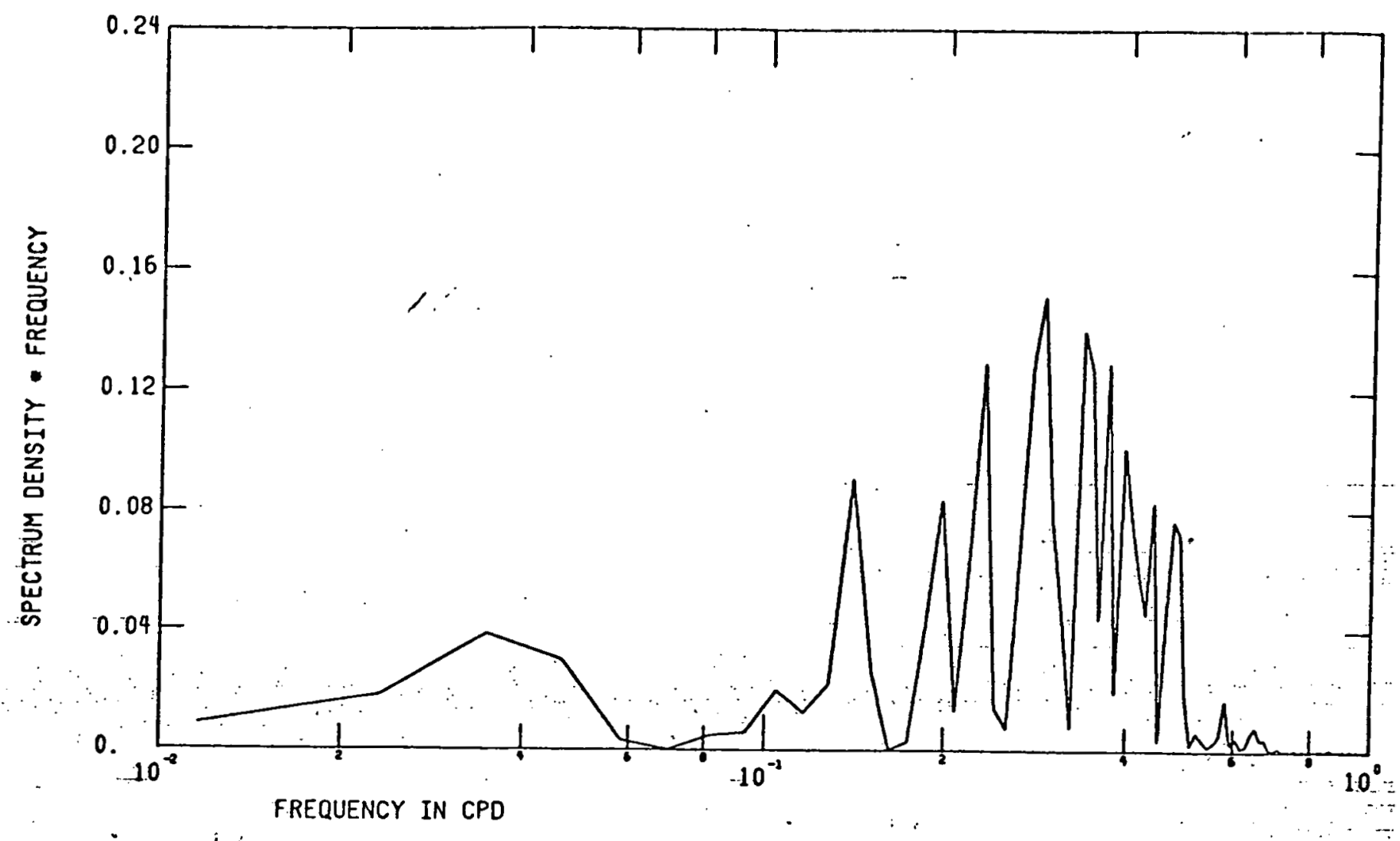

ENDECO $318 \vee$ COMP 6AUG75 2DLP

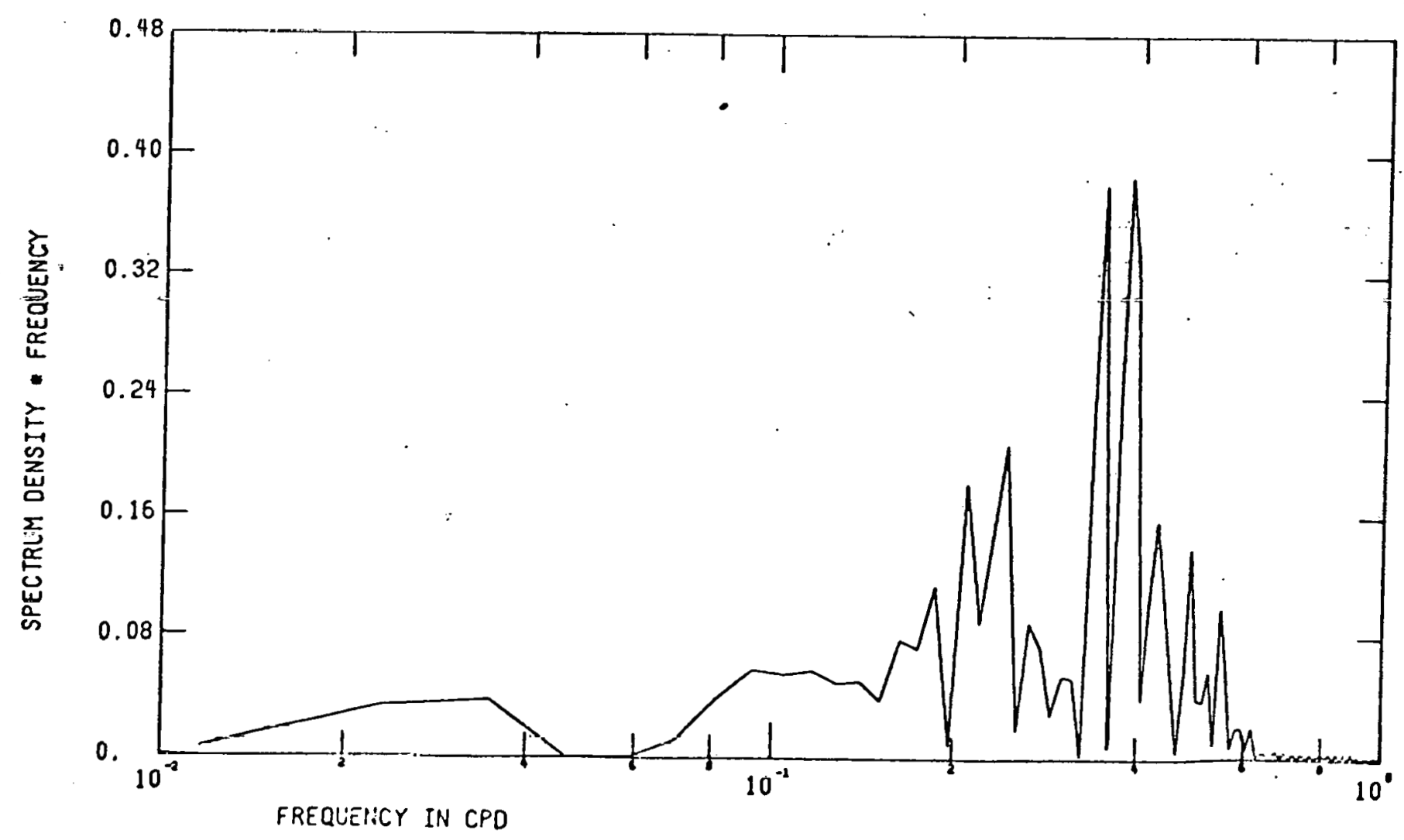

Figure 11. 

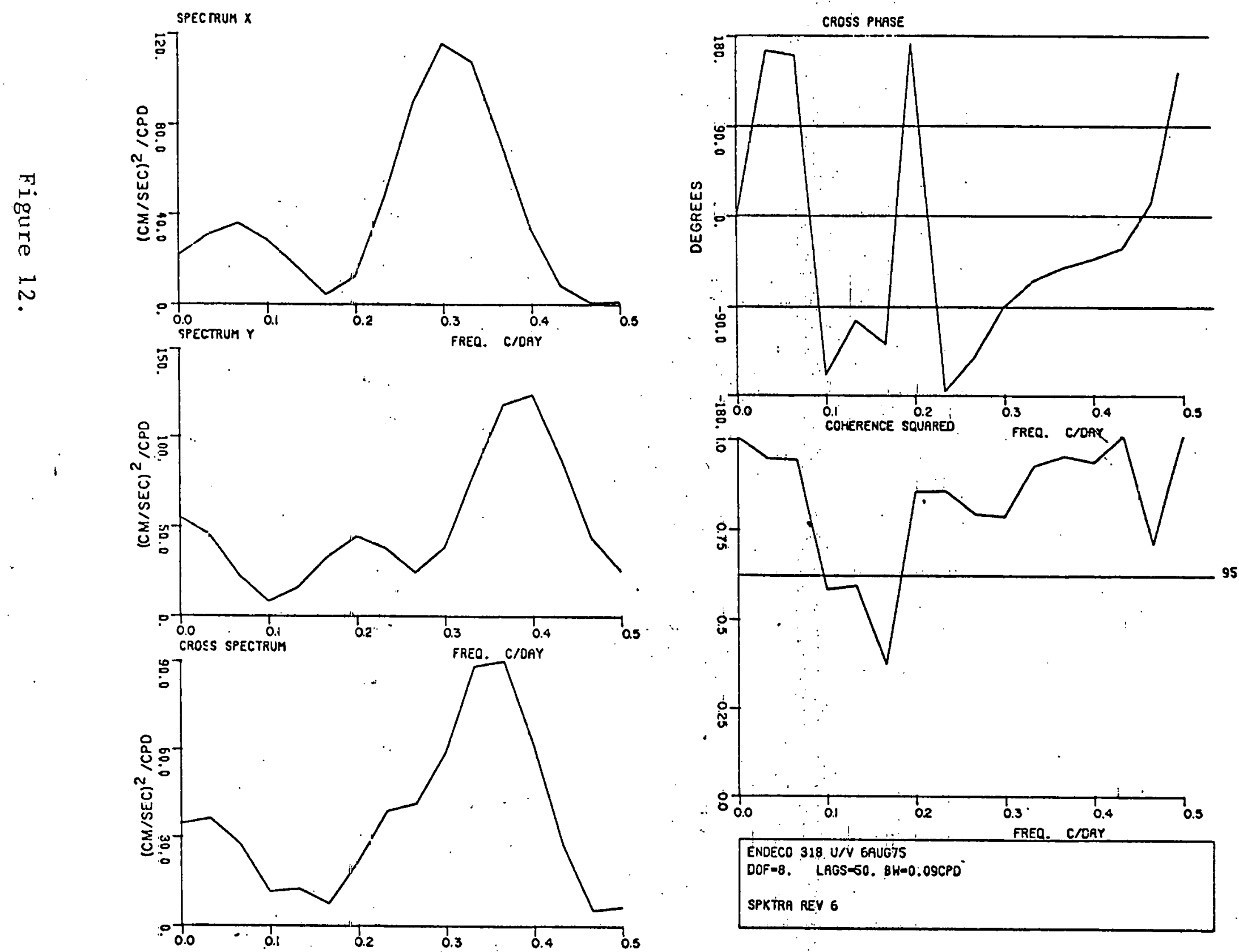


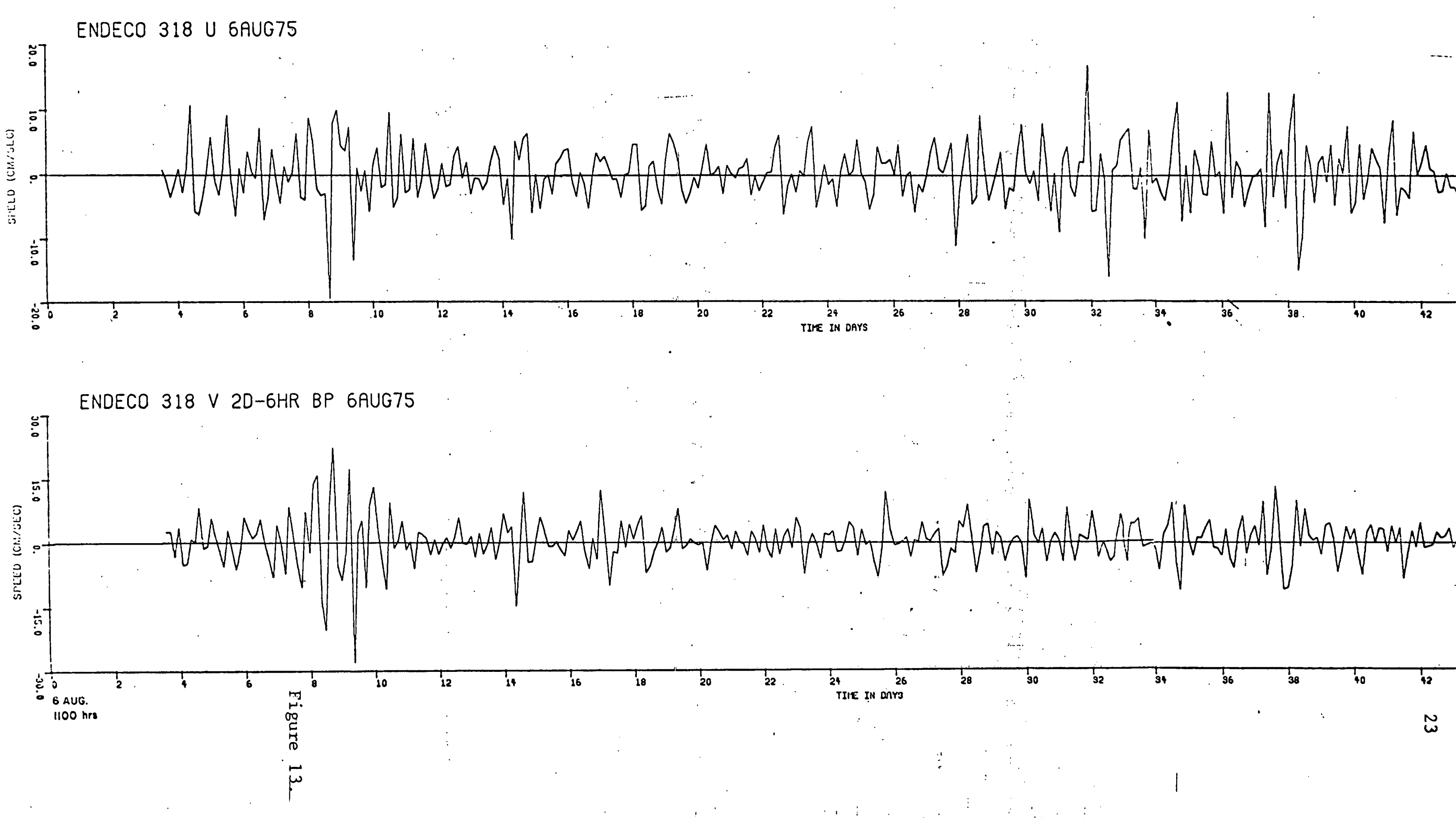




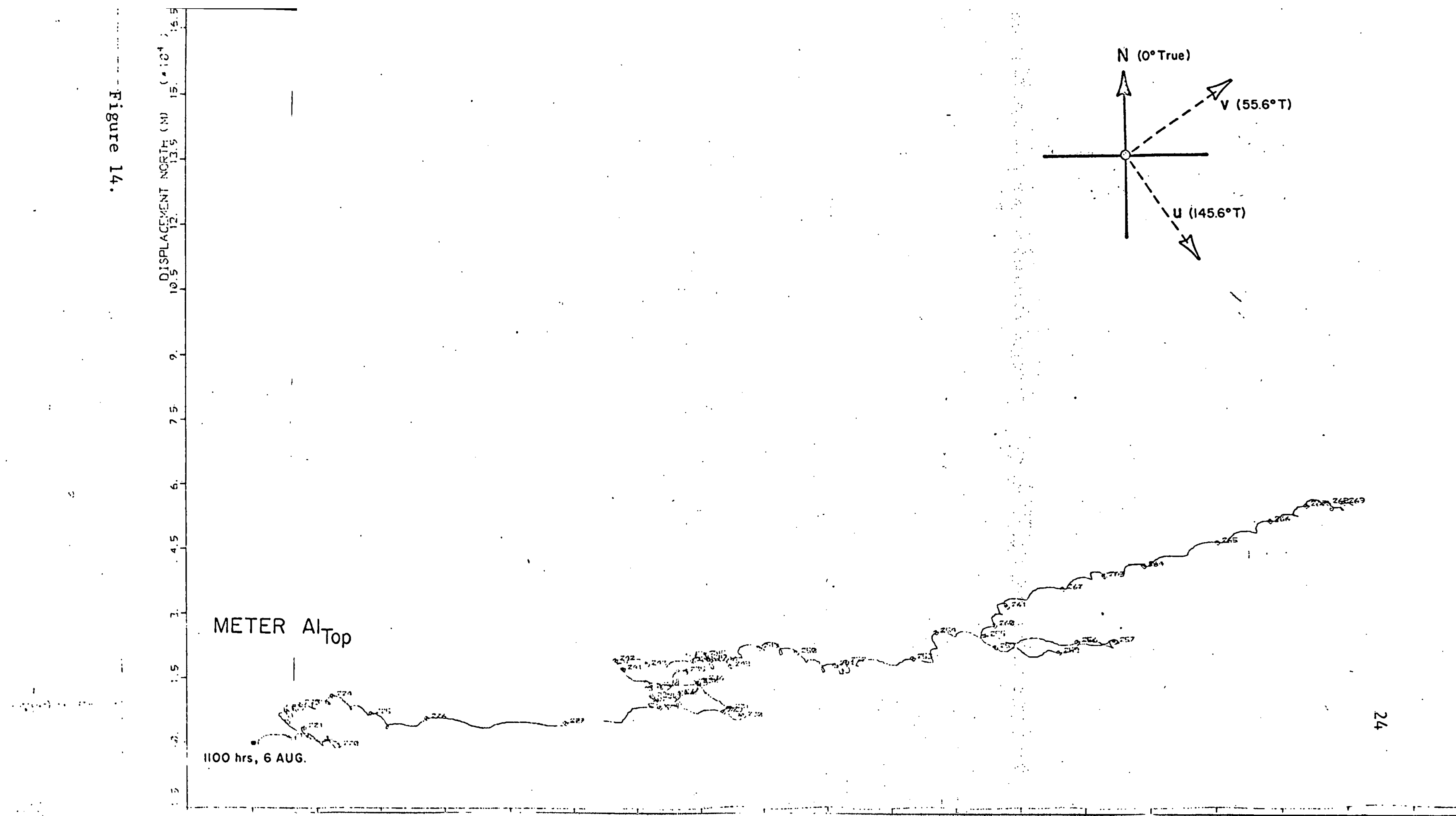


ENNEECO 318 GAUG-25SEP 75
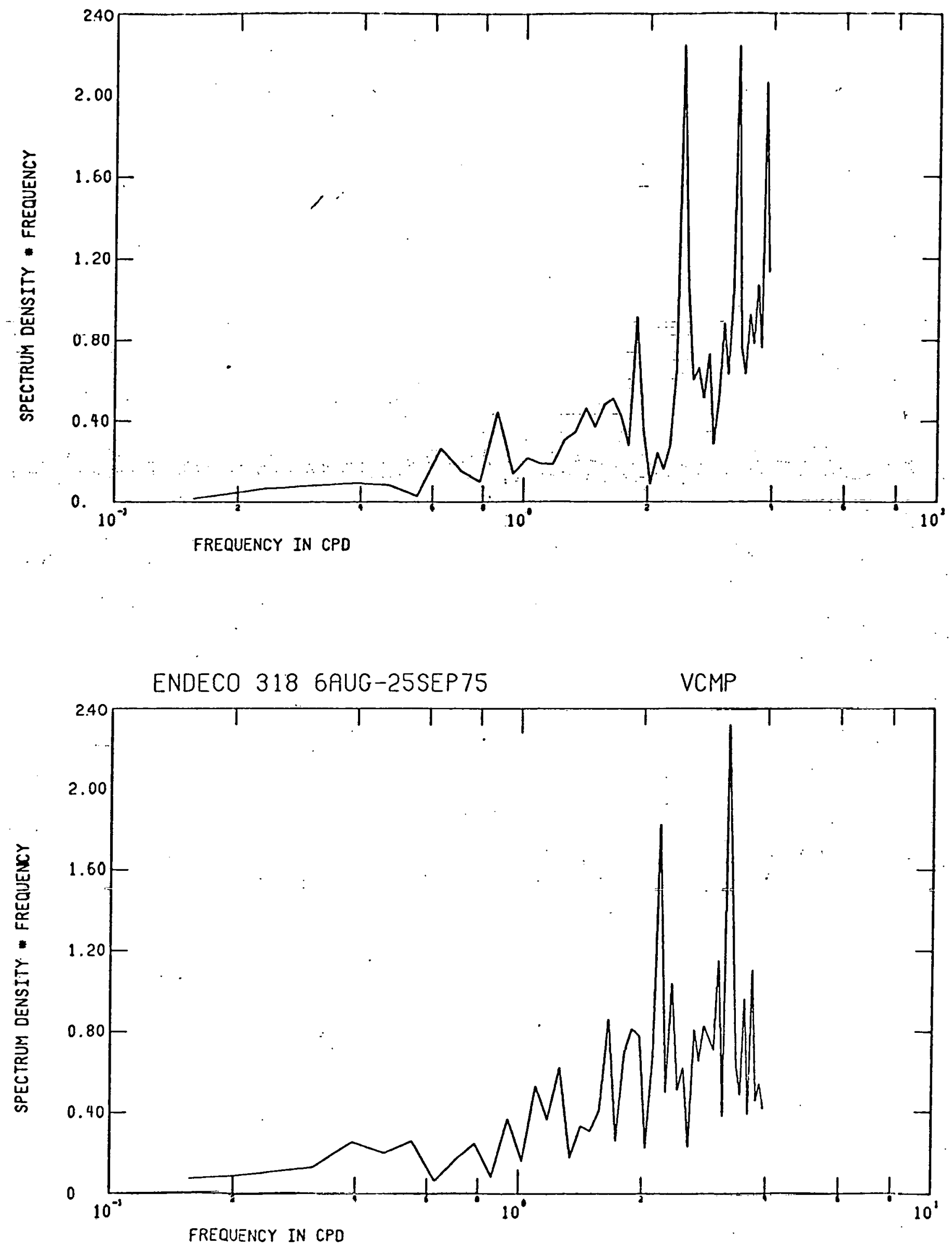

Figure 15. 


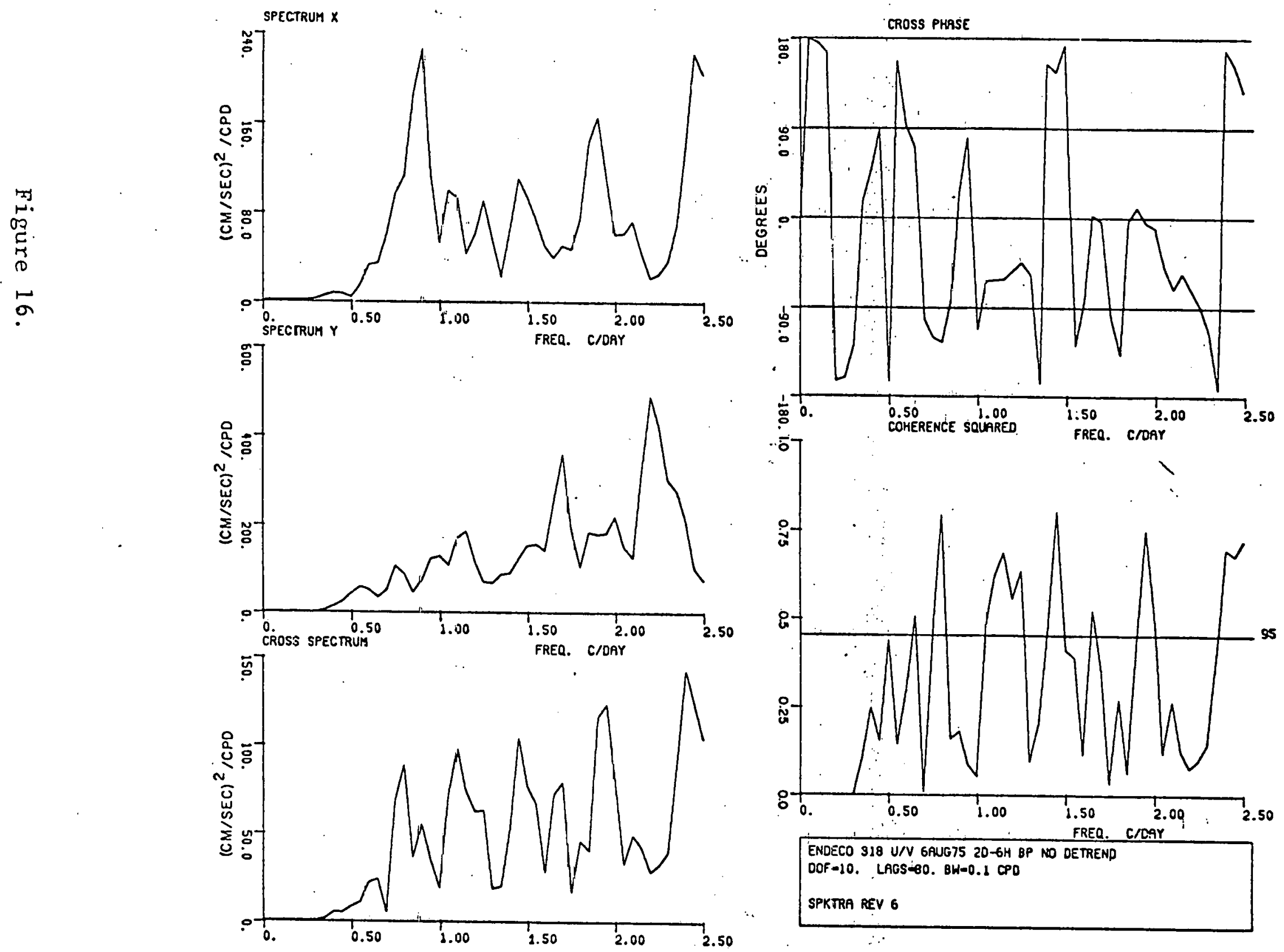



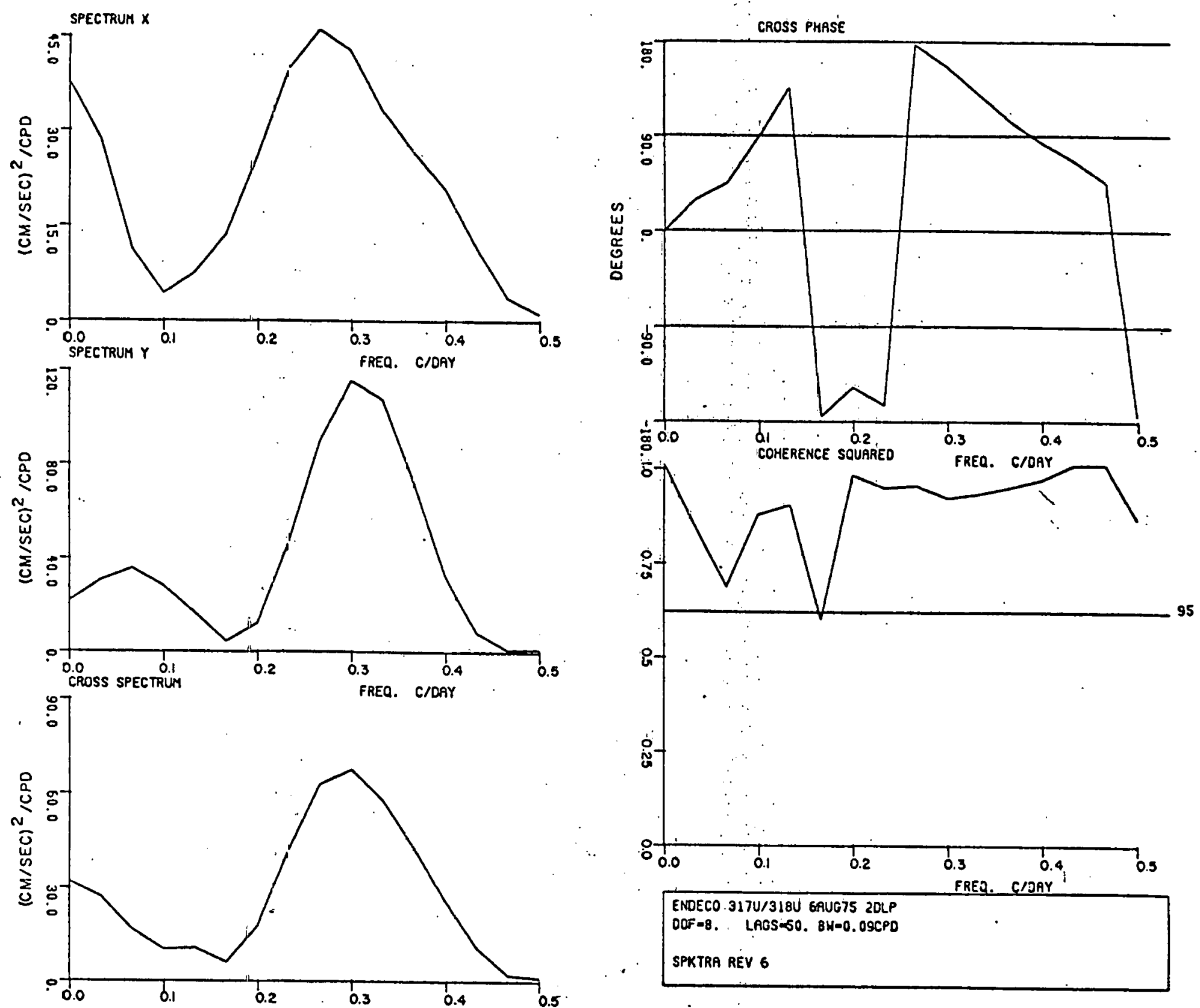
等.
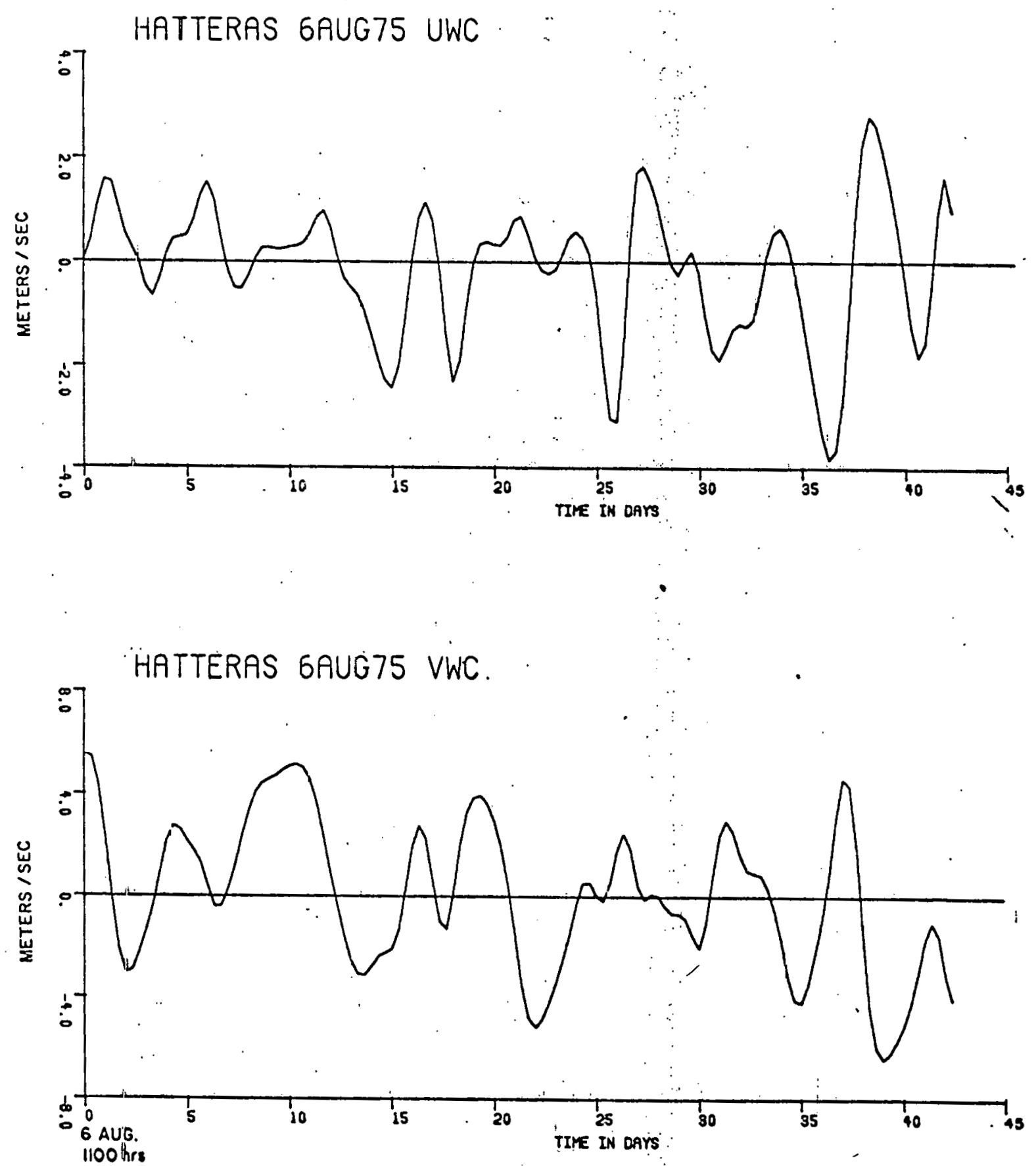
3
09
0
0
0
0
0

HATTERAS 6AUG75 TEMP
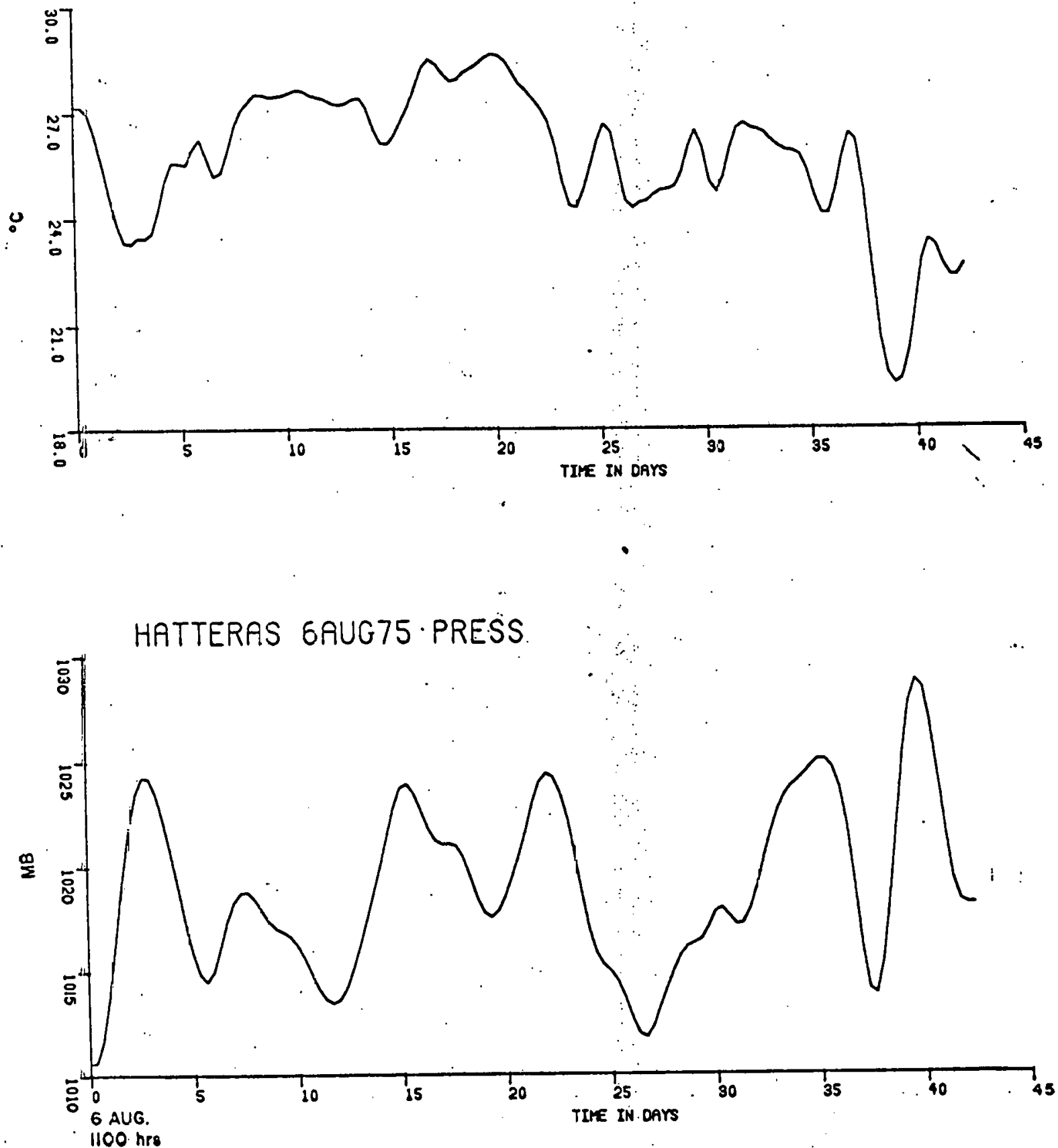
HATTERAS GAUG75 UWC

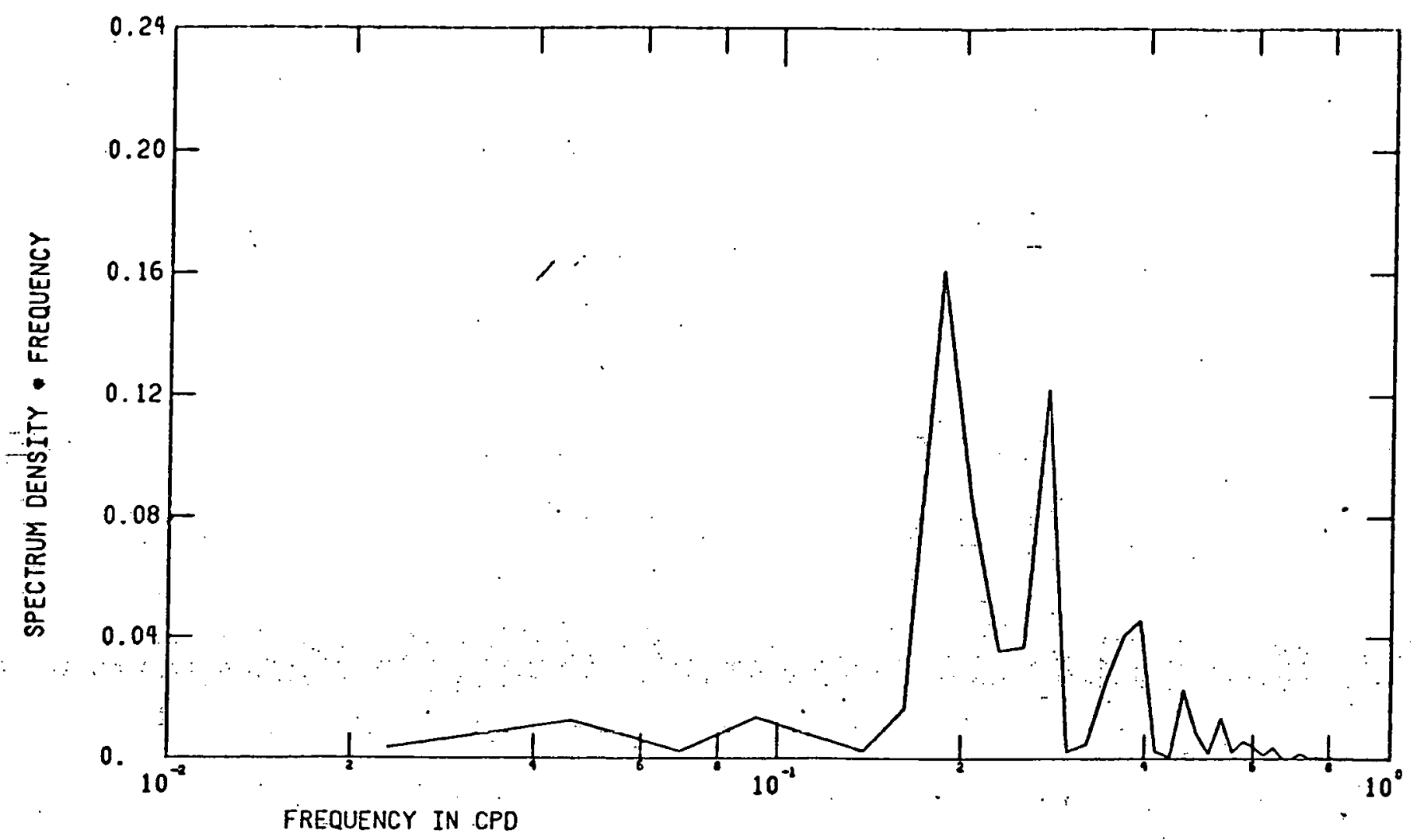

HATTERAS 6AUG75 VWC

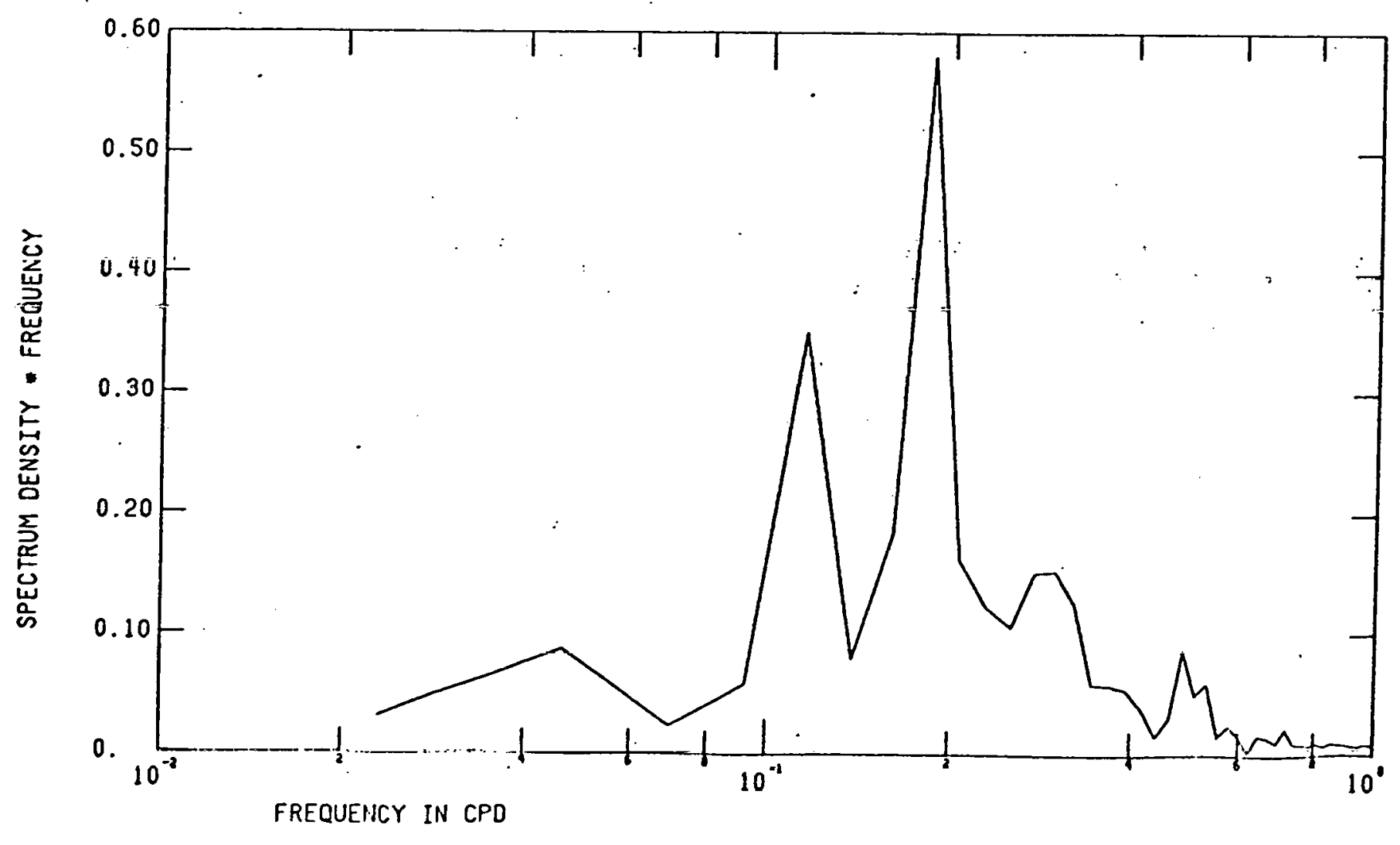

Figure 20. 
HATTERAS GRUG75. TEMP

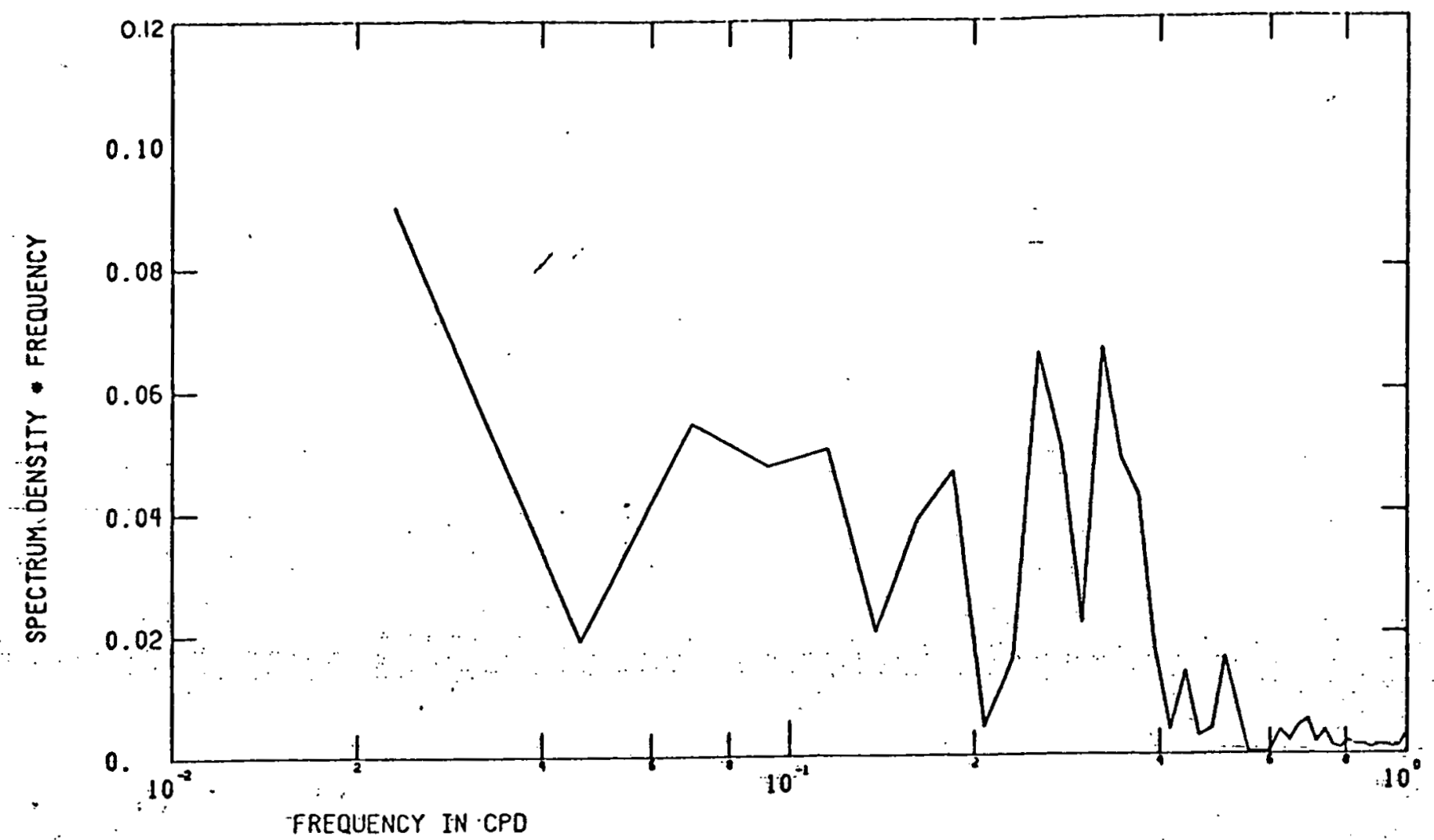

HATTERAS 6AUG75 PRESS

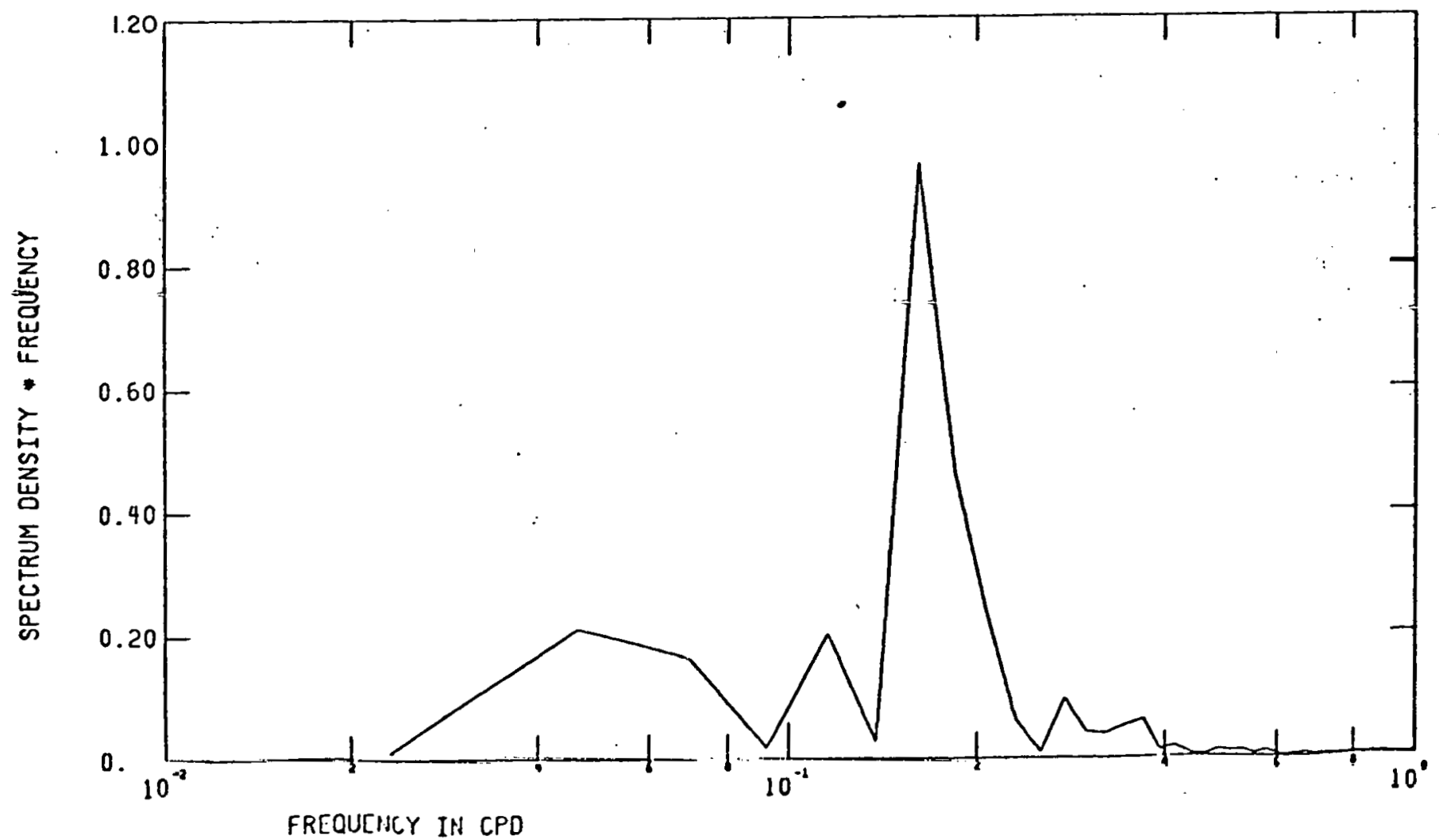

Figure 21. 

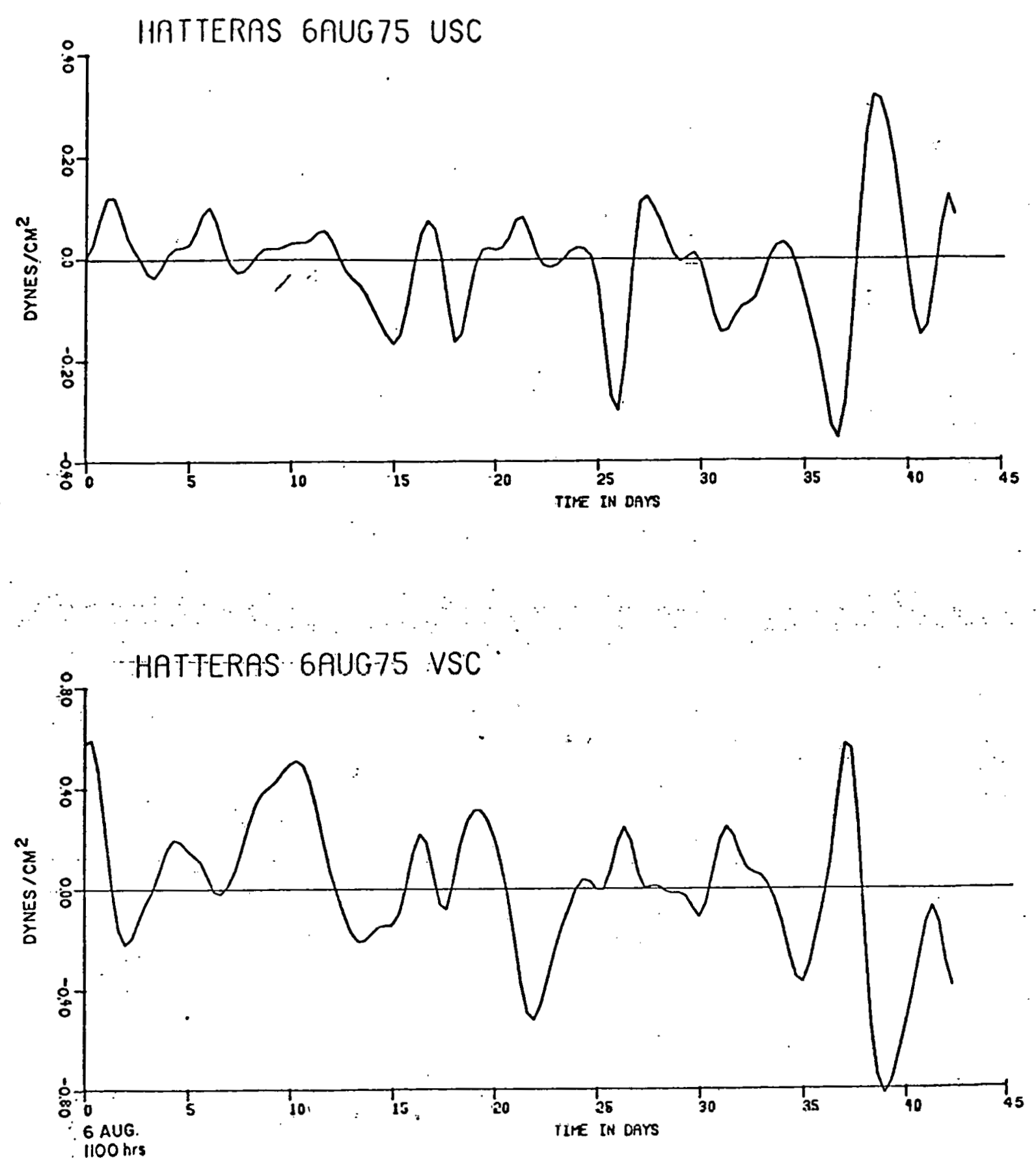

HATTERAS STRESS 2DLP

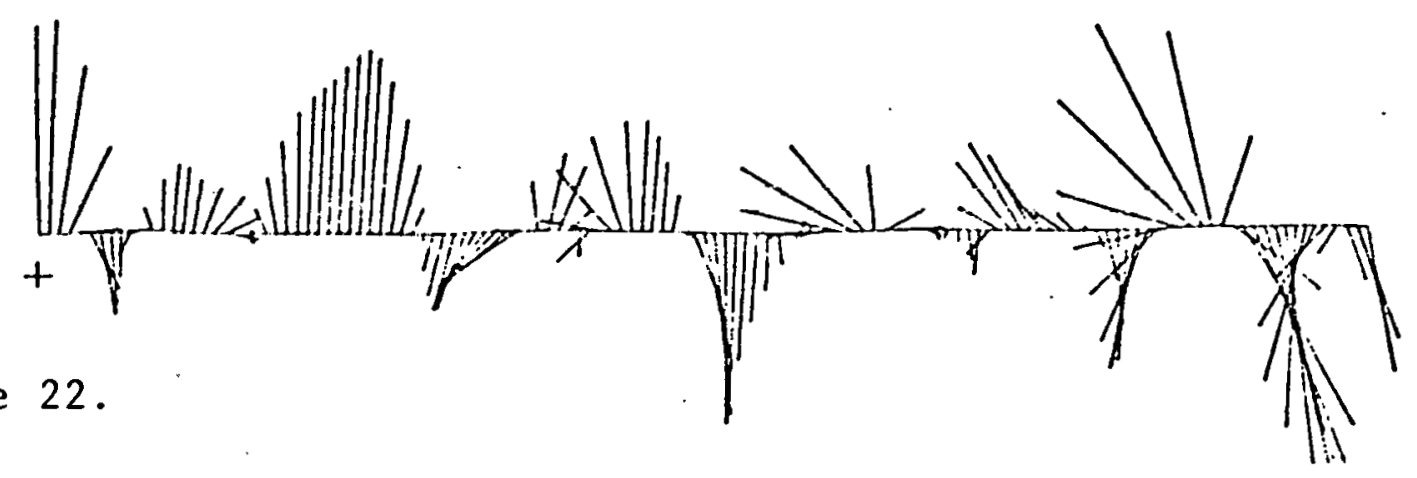

Figure 22. 
HATTERAS GAUG75 USC

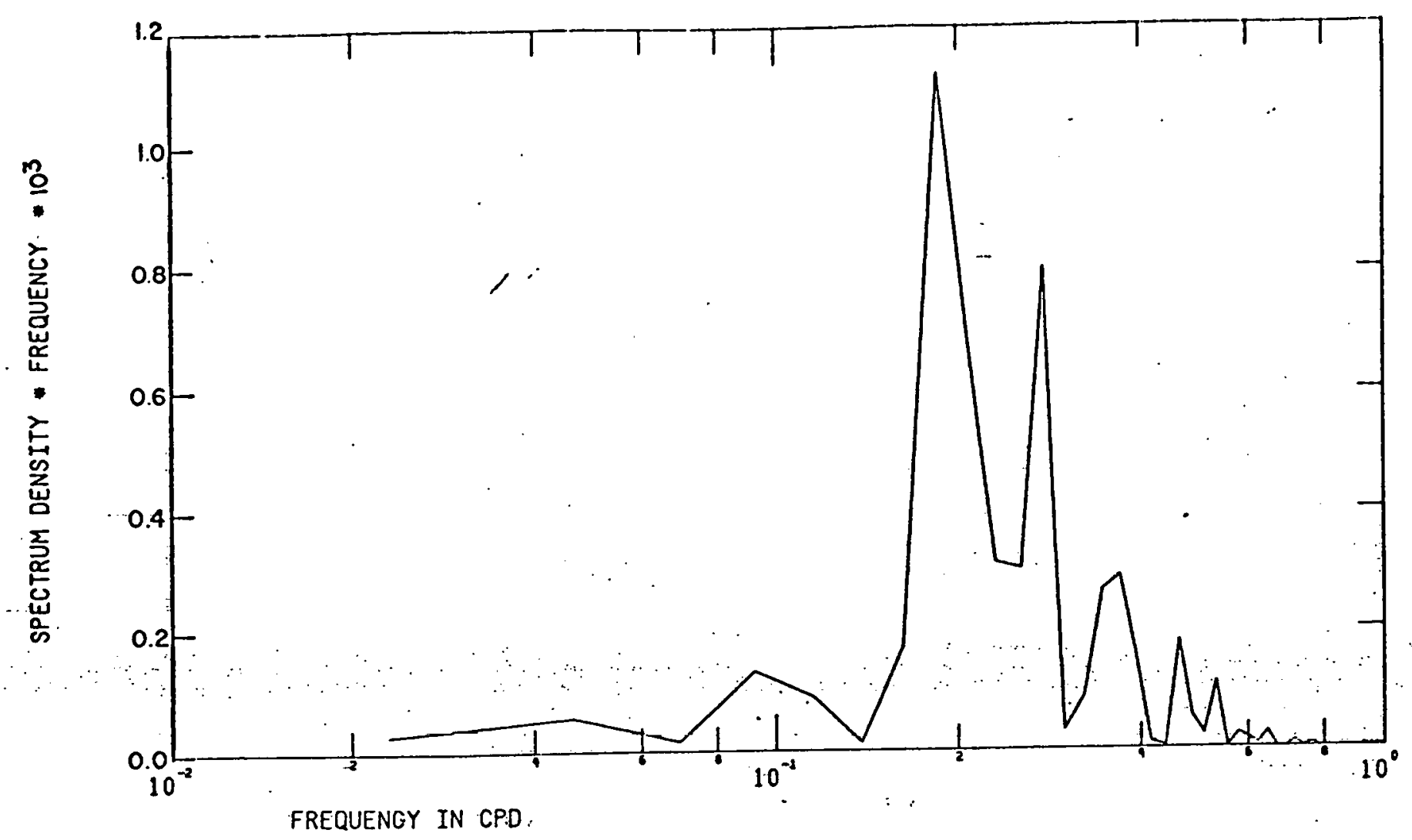

HATTERAS 6AUG75 VSC

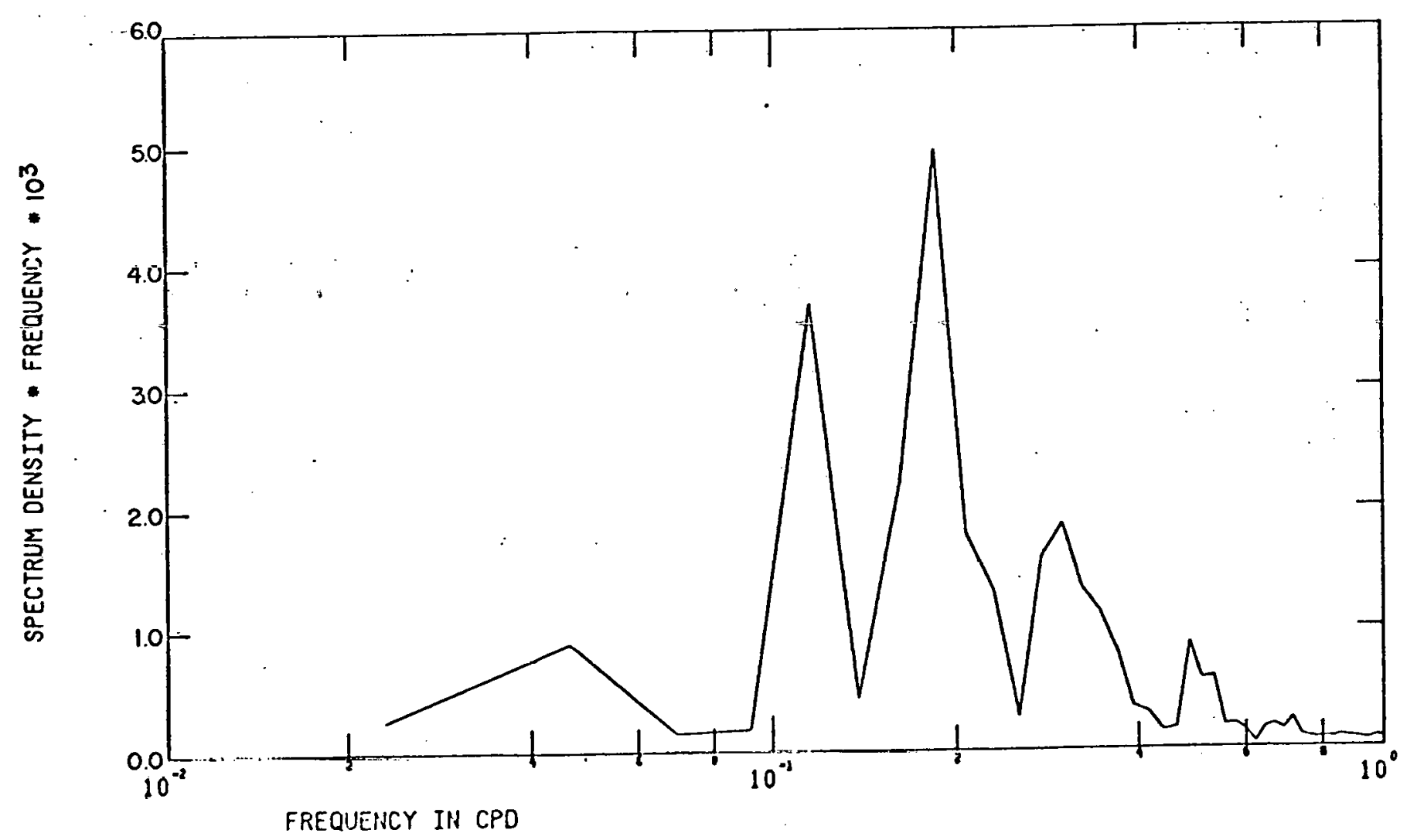

Figure 23. 


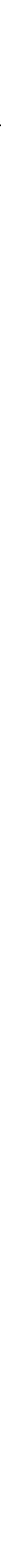




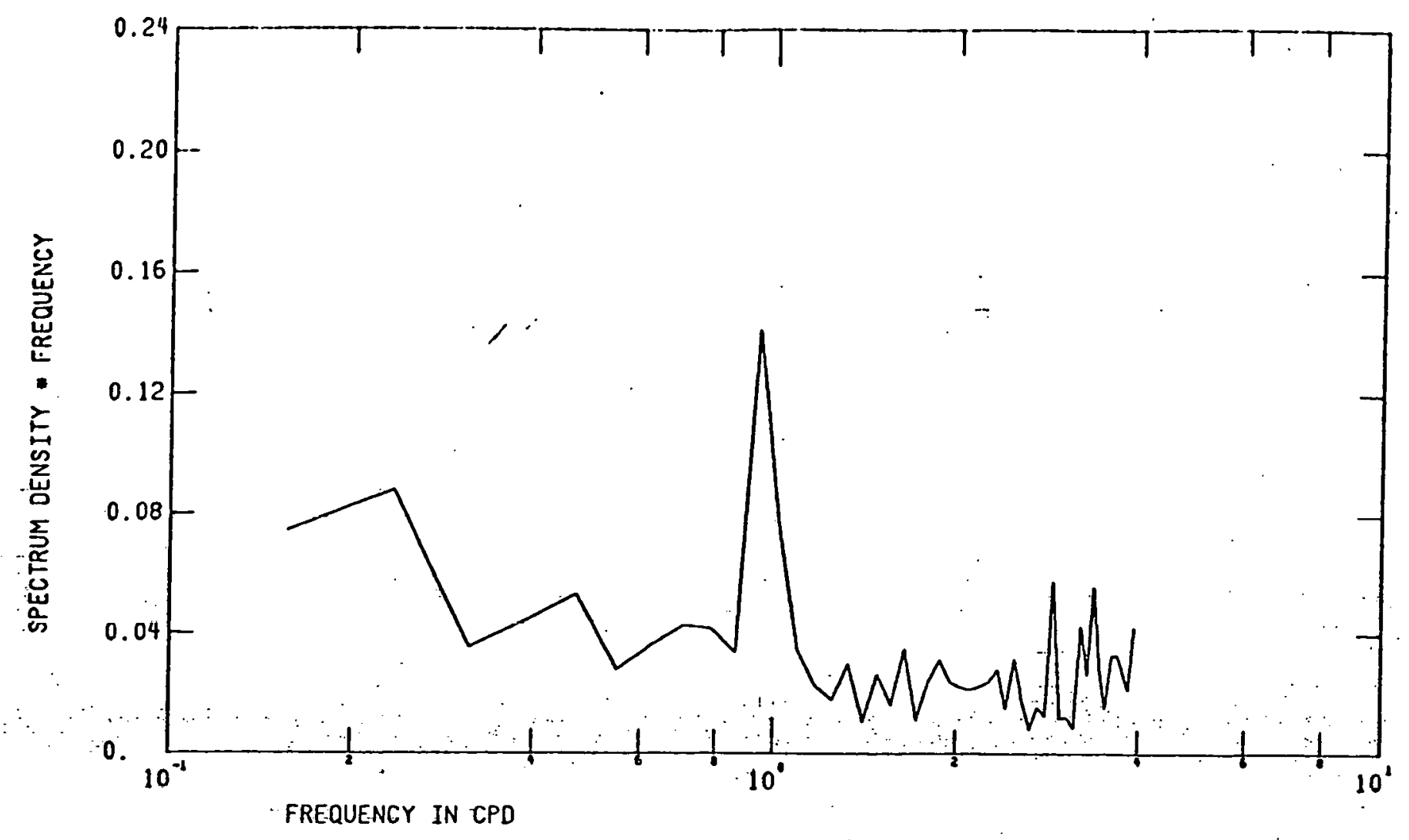

HAT VWC .6AUG75 ORIG DATA

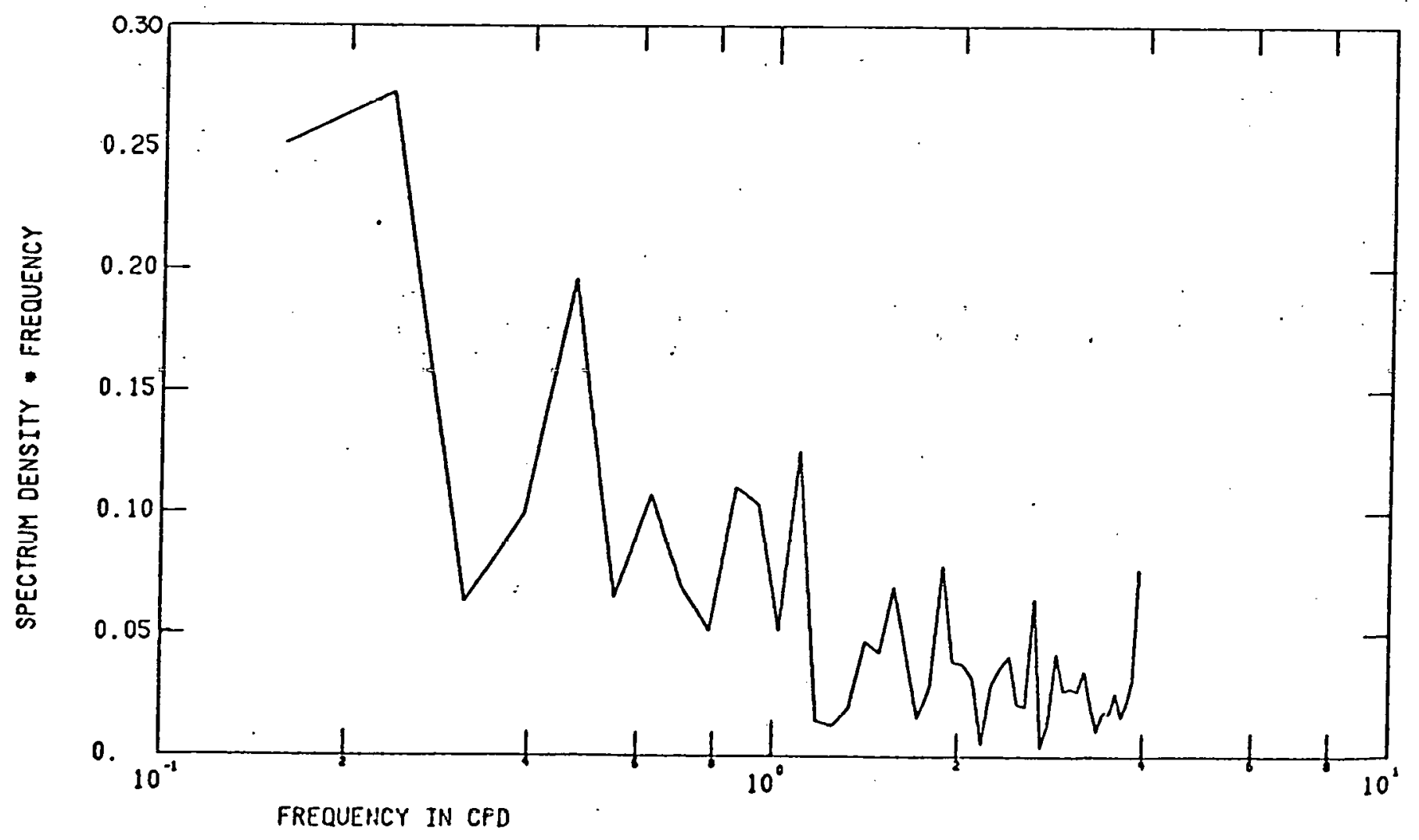

Figure 25. 
ENUECO 318 GAUG75 2DLP.

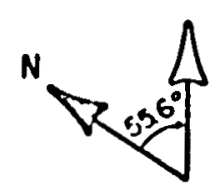

ENUECO 318 GAUG75 2DLP.

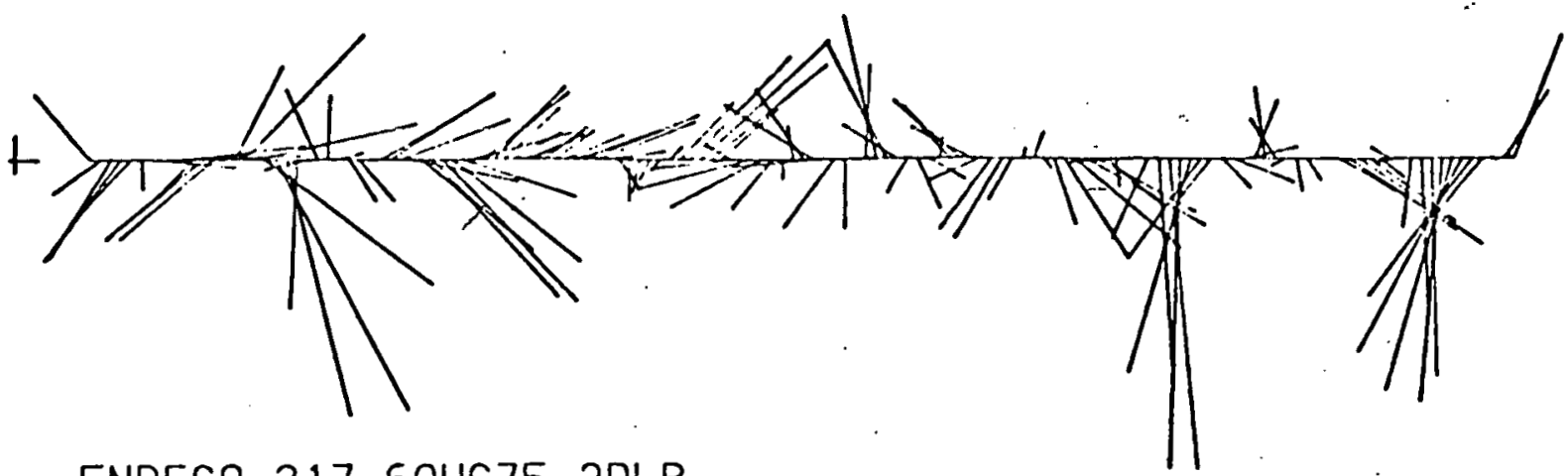

ENDECO 317 6AUG75 2DLP

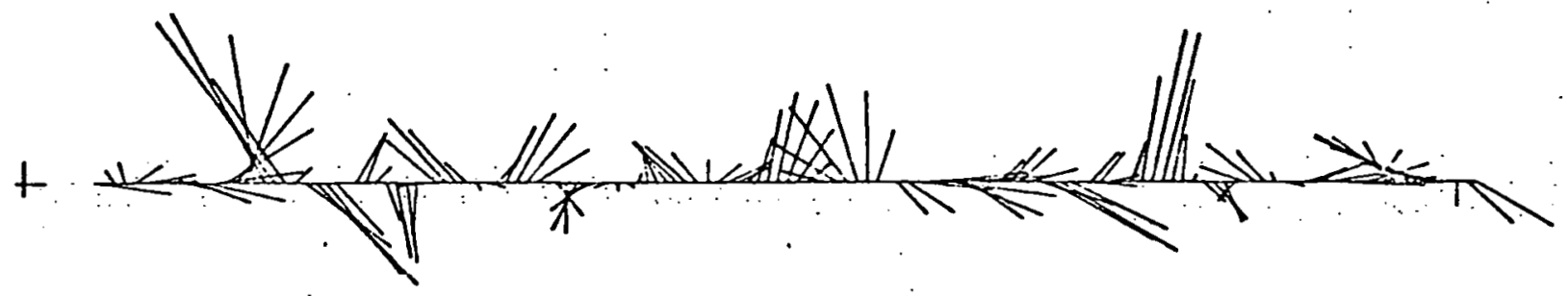

ENDECO 247 6AUG75 2DLP
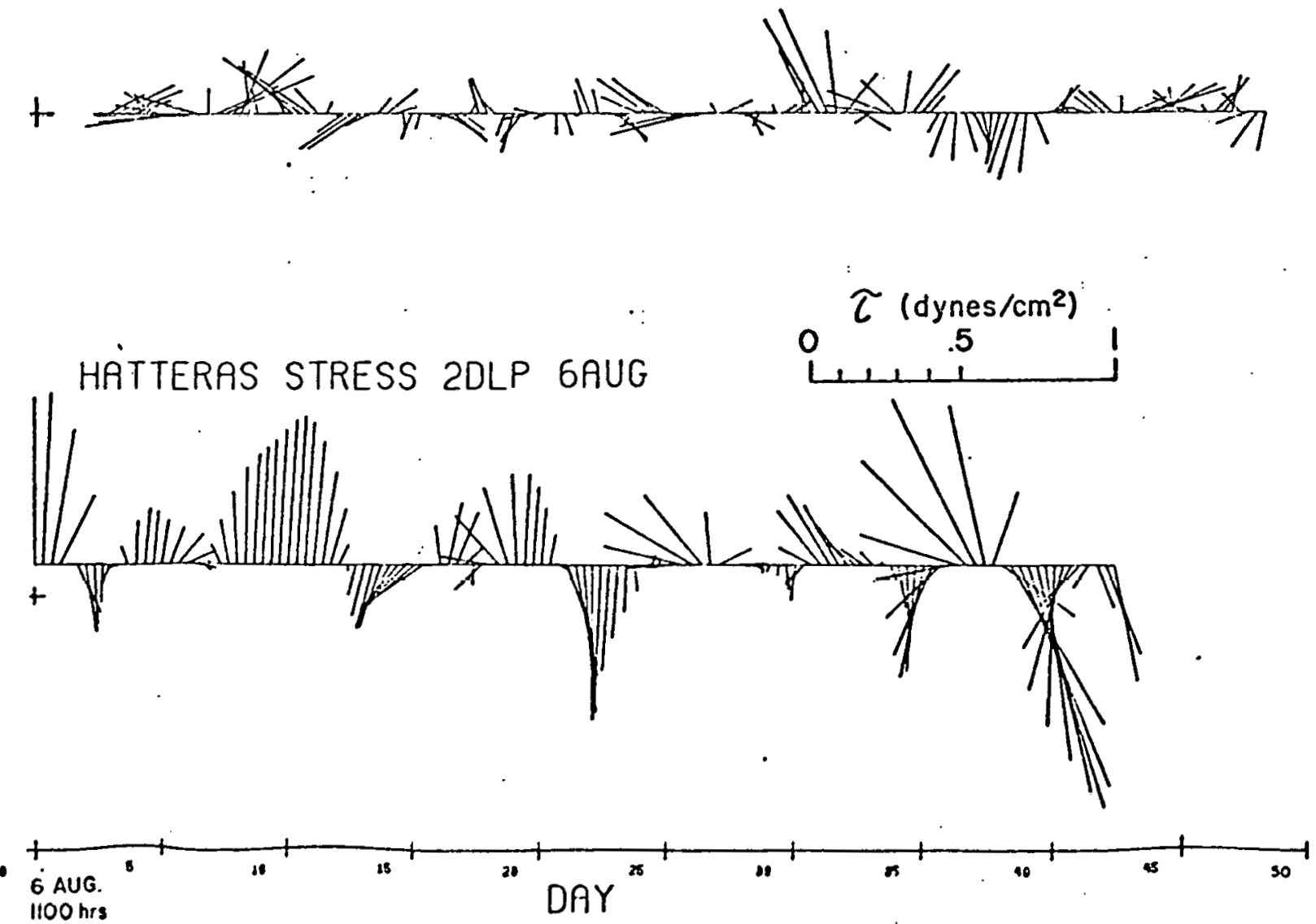

Figure 26. 

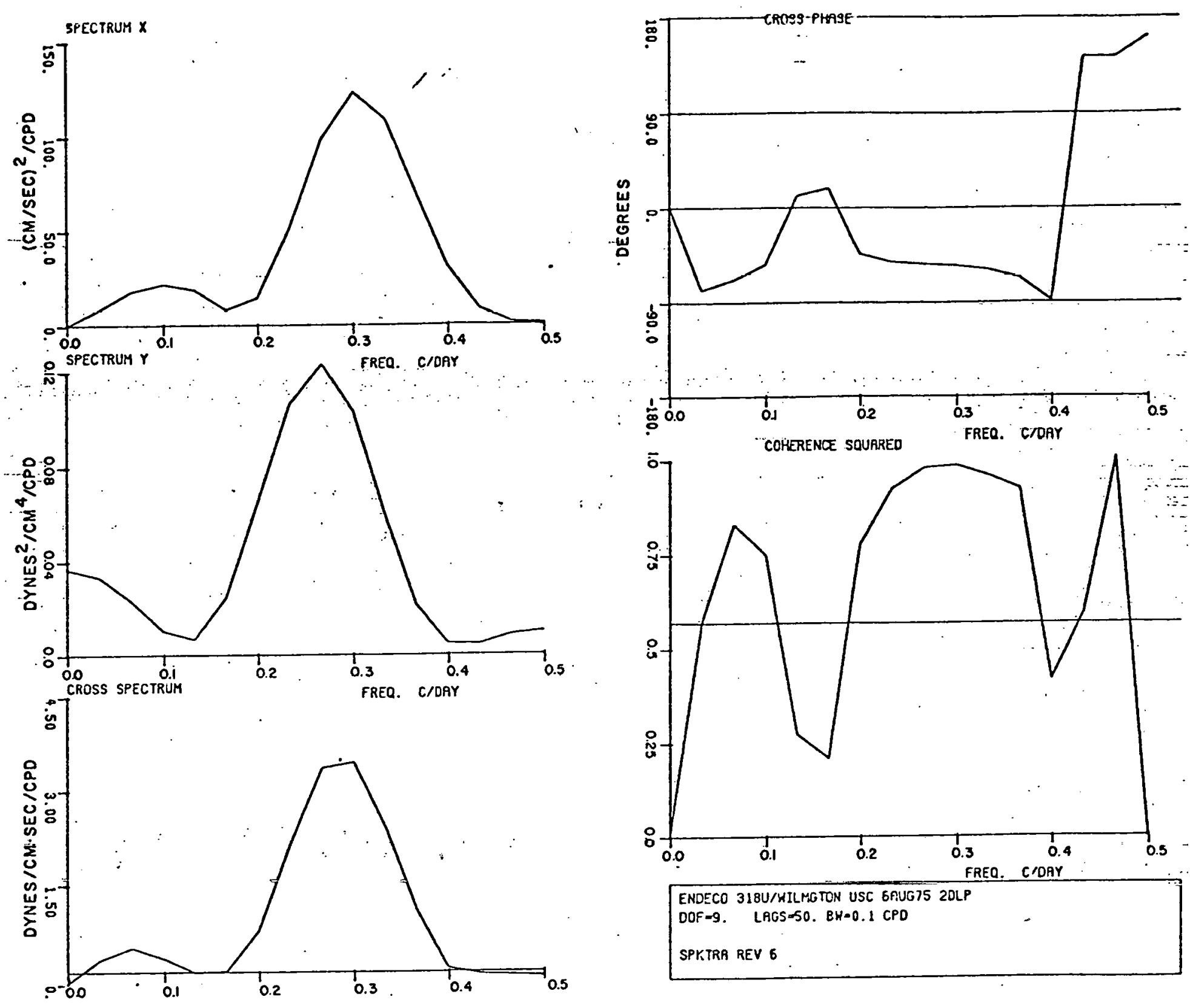

Figure 27. 
$\stackrel{\infty}{m}$
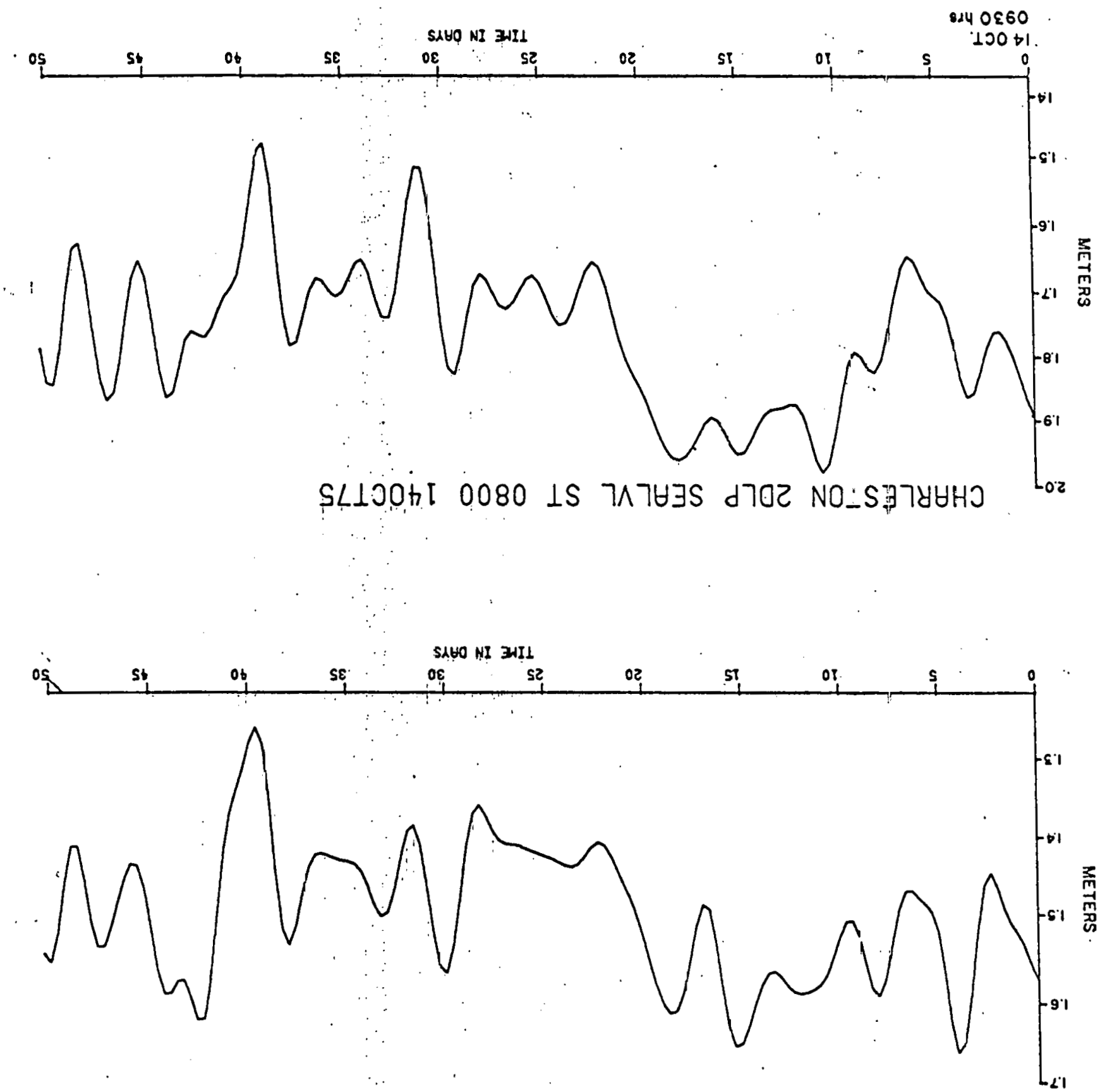

$\underset{\sim}{\infty}$

SLLOOtI 0080 LS $7 \wedge 7 \forall \exists S$ dרOZ NOLONIWרIM 


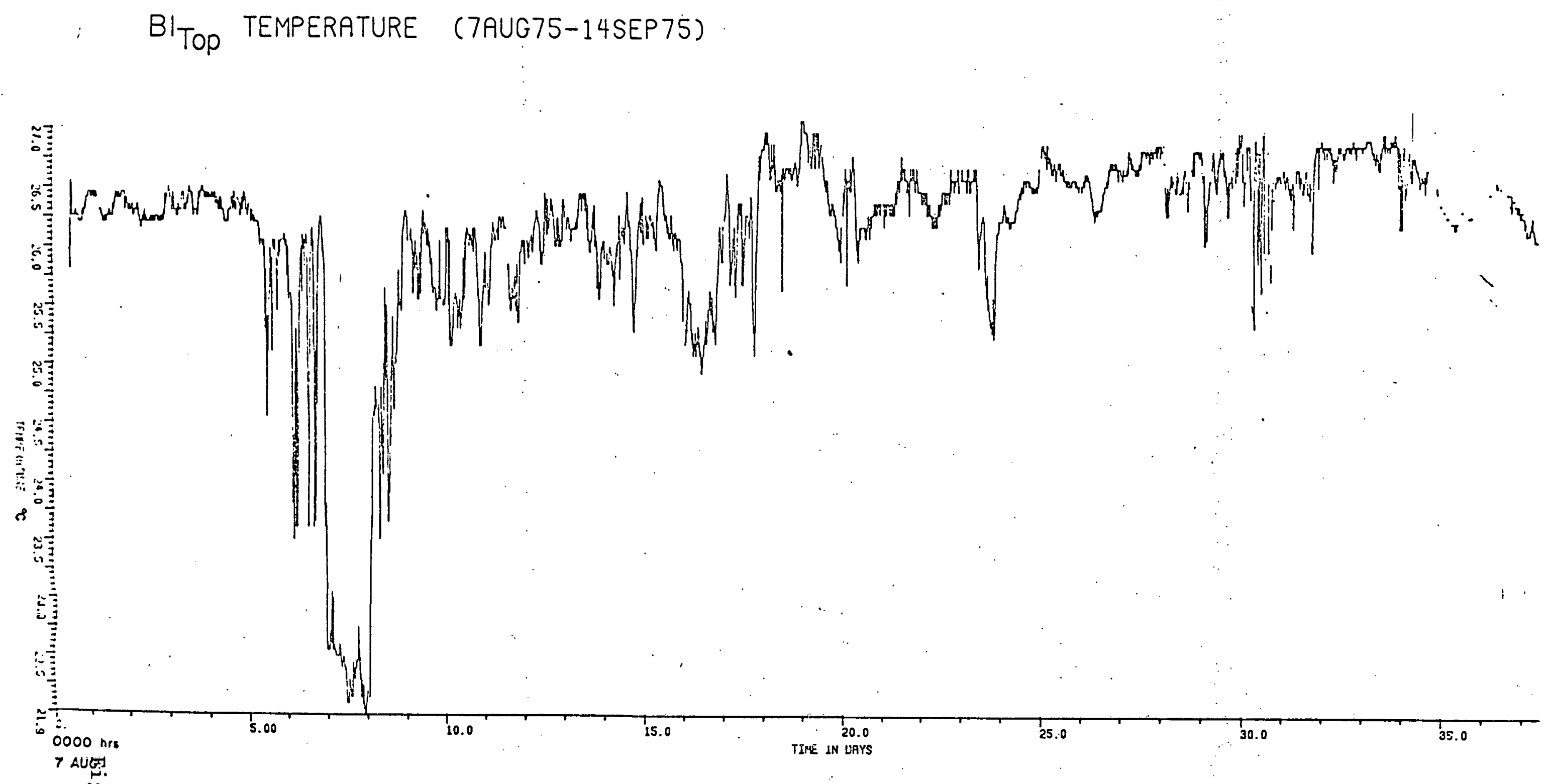


Summary of Accomplishments:

1. Equipment acquisition

a. 2 Aanderaa RCM-4 current speed and direction, conductivity, temperature and pressure monitoring sensors

b. 1 AMF Accoústic Release Mechanism

c. I AMF Bottom Release/Command Confirm System

d. Mooring/Laboratory Supplies

2. Computer program-development and data management for:

a. Time Series Analysis programs for Sea Level, Meteorological, current temperature and pressure data

3. Deployment/Retrieval of 6 moorings in Onslow Bay June.September, 1976 and deployment of 6 moorings -in Onslow $\therefore$ and Long Bays, December, 1976

4. Five Onslow Bay "intrusion study" cruises

5. Publications and Conference Papers as follows:

a. Publications Submitted to Reviewed Journals

1. McClain, C., N. Huang and L. J. Pietrafesa; 1977. Effects of a radiative type boundary condition of shelf circulation. Journal Physical Oceanography.

b. Papers in Preparation

1. Hofmann, E., L. J. Pletrafesa, L. Atkinson, G. Paffenhofer, W. Dunstan, 1977. "Vertical Plane Nutrient Distribution in Coastal Waters, Theory and Observations." Journal of Estuarine and Coastal Marine Sci. 


\section{c. Technical Reports}

1. Pletrafesa, L., D. Brooks, R. D'Amato, L. Atkinson. 1977. Onslow Bay Physical Dynamical Experiments, Summer-Fall, 1975. North Carolina State Unlversity Technical Report. 77-4.

2. Pietrafesa, L., D. Brooks, L. Atkinson, R. D'Amato, J. Bane, 1976. Preliminary Results of Observations In Onslow Bay, 1975. North Carolina State University Technical Report. 76-5.

3. Hofmann, E., L. Pietrafesa, L. Atkinson, G. Paffenhofer, W. Duristan, 19.77. A Mathematical Model of Nutrient Distribution in Coastal Waters. North Carolina State University Technical Report $77-2$. 